\title{
Peripheral CB1 cannabinoid receptor blockade improves cardiometabolic risk in mouse models of obesity
}

\author{
Joseph Tam,,1 V. Kiran Vemuri, ${ }^{2}$ Jie Liu, ${ }^{1}$ Sándor Bátkai, ${ }^{1}$ Bani Mukhopadhyay, ${ }^{1}$ Grzegorz Godlewski, \\ Douglas Osei-Hyiaman,, ${ }^{1}$ Shinobu Ohnuma, ${ }^{3}$ Suresh V. Ambudkar, ${ }^{3}$ James Pickel, 4 \\ Alexandros Makriyannis, ${ }^{2}$ and George Kunos ${ }^{1}$

\begin{abstract}
${ }^{1}$ Laboratory of Physiologic Studies, National Institute on Alcohol Abuse and Alcoholism, National Institutes of Health, Bethesda, Maryland, USA. ${ }^{2}$ Center for Drug Discovery, Northeastern University, Boston, Massachusetts, USA. ${ }^{3}$ Laboratory of Cell Biology, National Cancer Institute, National Institutes of Health, Bethesda, Maryland, USA. ${ }^{4}$ Laboratory of Genetics, National Institute of Mental Health, National Institutes of Health, Bethesda, Maryland, USA.
\end{abstract}

\begin{abstract}
Obesity and its metabolic consequences are a major public health concern worldwide. Obesity is associated with overactivity of the endocannabinoid system, which is involved in the regulation of appetite, lipogenesis, and insulin resistance. Cannabinoid-1 receptor $\left(C_{1} R\right)$ antagonists reduce body weight and improve cardiometabolic abnormalities in experimental and human obesity, but their therapeutic potential is limited by neuropsychiatric side effects. Here we have demonstrated that $C^{C B}{ }_{1} R$ neutral antagonist largely restricted to the periphery does not affect behavioral responses mediated by $C_{1} R$ in the brains of mice with genetic or diet-induced obesity, but it does cause weight-independent improvements in glucose homeostasis, fatty liver, and plasma lipid profile. These effects were due to blockade of $C_{1} R$ in peripheral tissues, including the liver, as verified through the use of $C_{1} R$-deficient mice with or without transgenic expression of $C B_{1} R$ in the liver. These results suggest that targeting peripheral $C_{1} R$ has therapeutic potential for alleviating cardiometabolic risk in obese patients.
\end{abstract}

\section{Introduction}

Endocannabinoids are endogenous lipid mediators that interact with the same $G$ protein-coupled receptors $-\mathrm{CB}_{1} \mathrm{R}$ and $\mathrm{CB}_{2} \mathrm{R}$ - that recognize plant-derived cannabinoids, and they regulate a broad range of physiological functions. $\mathrm{CB}_{1} \mathrm{Rs}$ are expressed at very high levels in the brain but are also present at much lower yet functionally relevant concentrations in various peripheral tissues, whereas the expression of $\mathrm{CB}_{2} \mathrm{Rs}$ is largely limited to cells of the immune and hematopoietic systems. Activation of $\mathrm{CB}_{1} \mathrm{R}$ results in increased appetite, insulin resistance, and increased hepatic lipogenesis, which suggests the involvement of the endocannabinoid/ $\mathrm{CB}_{1} \mathrm{R}$ system in obesity and its metabolic consequences (1). Indeed, obesity and its metabolic complications are characterized by an overactive endocannabinoid system (2-5), and chronic treatment with $\mathrm{CB}_{1} \mathrm{R}$ antagonists leads to weight loss and improved cardiometabolic risk profile in obese rodents $(6,7)$ and humans $(8-11)$. However, concern over neuropsychiatric side effects, including anxiety, depression, and suicidal ideation (12), prevented approval of the first-in-class $\mathrm{CB}_{1} \mathrm{R}$ antagonist rimonabant in the United States and led to its withdrawal from the European market as well as the withdrawal of related compounds from preclinical development (13). Although the exact role of the endocannabinoid system in the control of mood and anxiety-like behaviors is not clear, $\mathrm{CB}_{1} \mathrm{R}$ in the prefrontal cortex, amygdala, and the mesolimbic dopaminergic reward pathway have been linked to the control of these behaviors (14). On the other hand, $\mathrm{CB}_{1}$ Rs are also present in peripheral tissues including the liver $(15-17)$, skeletal muscle $(18,19)$, endocrine

Authorship note: Joseph Tam and V. Kiran Vemuri contributed equally to this work. Conflict of interest: The authors have declared that no conflict of interest exists. Citation for this article: J Clin Invest. 2010;120(8):2953-2966. doi:10.1172/JCI42551. pancreas $(20,21)$, and fat $(16,22,23)$, where their activation contributes to obesity-related metabolic and hormonal abnormalities (24-26). This suggests that selective targeting of peripheral $\mathrm{CB}_{1} \mathrm{R}$ may result in an improved hormonal-metabolic profile in obesity without the untoward behavioral effects observed following treatment with brain-penetrant $\mathrm{CB}_{1} \mathrm{R}$ antagonists. To this end, we have developed a potent, selective, orally bioavailable $\mathrm{CB}_{1} \mathrm{R}$ antagonist with limited brain penetrance, and tested its behavioral and metabolic activity profile in two experimental models of obesity as well as in transgenic mice with $\mathrm{CB}_{1} \mathrm{R}$ expression limited to the liver. The results indicate that selective targeting of peripheral $\mathrm{CB}_{1} \mathrm{R}$ has value in the management of cardiometabolic risk in obesity.

\section{Results}

AM6545 is a non-brain-penetrant neutral $C B_{1} R$ antagonist. First-generation $\mathrm{CB}_{1} \mathrm{R}$ antagonists, such as rimonabant, are highly lipid soluble and readily penetrate the blood-brain barrier. In order to reduce brain penetrance, we introduced several modifications into the structure of rimonabant. The analog AM6545 [5-(4-[4-cyanobut1-ynyl]phenyl)-1-(2,4-dichlorophenyl)-4-methyl- $N$-(1,1-dioxo-thiomorpholino)- $1 \mathrm{H}$-pyrazole-3-carboxamide] (Figure 1A) is less lipid soluble than rimonabant (estimated partition coefficient [log P], 3.3 vs. 6.4 for rimonabant) but retains high affinity and selectivity for $\mathrm{CB}_{1} \mathrm{R}$. In radioligand displacement assays, AM6545 has a $K_{I}$ of $3.3 \mathrm{nM}$ for $\mathrm{CB}_{1} \mathrm{R}$, which is similar to that of rimonabant, and greater than 100 -fold $\mathrm{CB}_{1} / \mathrm{CB}_{2}$ selectivity (Figure $1 \mathrm{~B}$ ). Unlike rimonabant, AM6545 does not reduce GTP $\gamma \mathrm{S}$ binding in mouse brain membranes and is therefore a neutral antagonist (Figure 1B). Importantly, AM6545 displays markedly reduced brain penetrance, as reflected by a brain/plasma concentration ratio of 0.03 following acute parenteral or oral administration and removal of intravascu- 

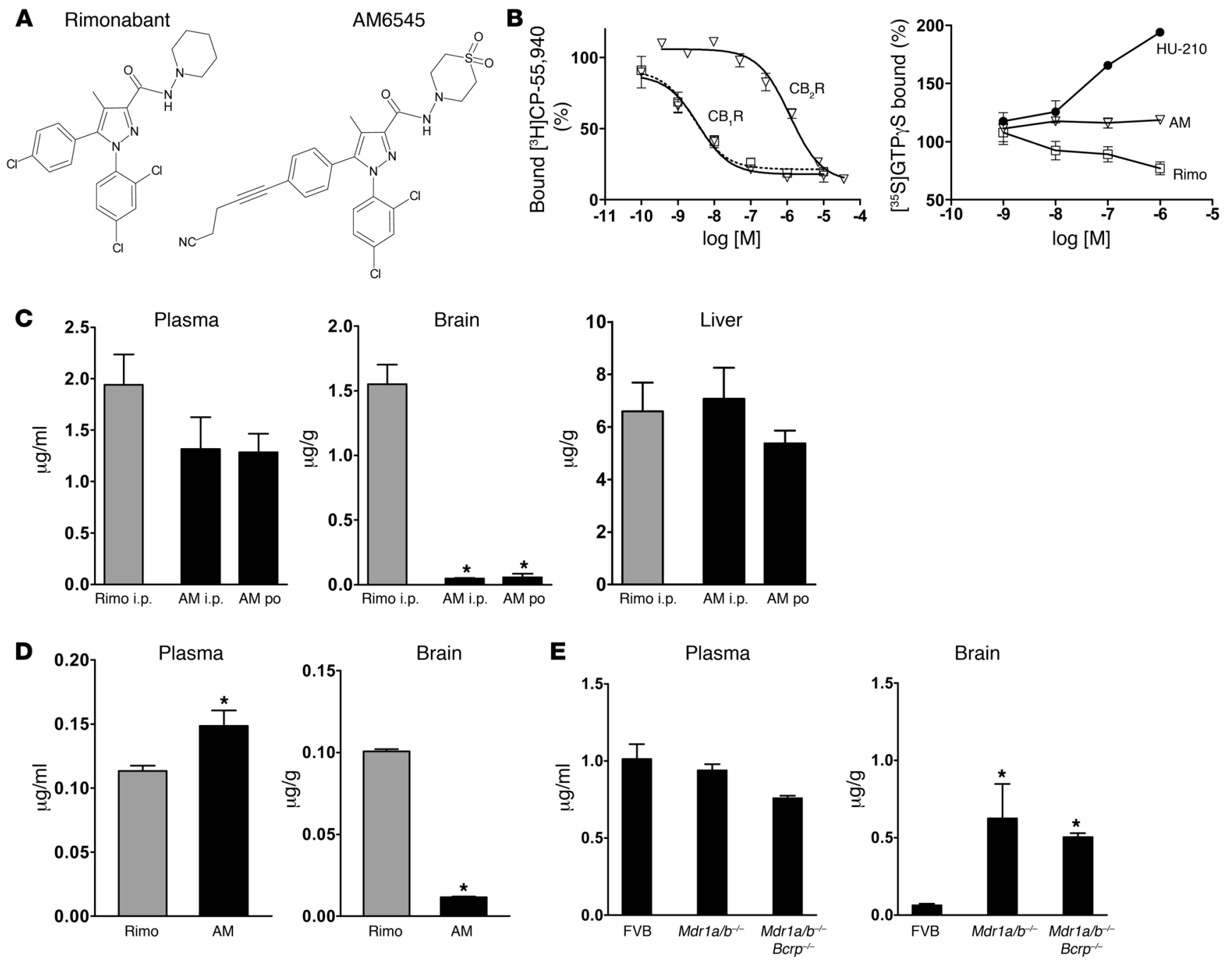

Figure 1

Chemical structure and pharmacological profile of AM6545. (A) Chemical structure of AM6545 and rimonabant. (B) In vitro interaction of antagonists with $\mathrm{CB}_{1} R$ and $\mathrm{CB}_{2} \mathrm{R}$ : Left: $K_{l}$ values for $\mathrm{CB}_{1} \mathrm{R}$ (AM6545: $3.3 \pm 0.8 \mathrm{nM}$, rimonabant: $\left.2.9 \pm 1.5 \mathrm{nM}\right)$ and $\mathrm{CB}_{2} \mathrm{R}(\mathrm{AM} 6545: 624 \pm 128 \mathrm{nM})$ were derived from displacement of $\left[{ }^{3} \mathrm{H}\right] \mathrm{CP}-55,940$ binding in mouse brain plasma membranes and membranes of HEK293 cells transfected with mouse $\mathrm{CB}_{2} \mathrm{R}$, respectively. Right: Agonist effect of HU-210, neutral antagonism by AM6545 (AM), and inverse agonism by rimonabant (Rimo), indicated by increase, no change, and decrease in GTP $\gamma S$ binding, respectively. Data represent percentage of stimulation over basal binding and are mean \pm SEM of 3 assays performed in triplicate. (C) Concentration of AM6545 and rimonabant in plasma, brain, and liver, 1 hour after i.p. or po administration by gavage of a dose of $10 \mathrm{mg} / \mathrm{kg}$. Data represent mean \pm SEM from 3 mice per group. ${ }^{*} P<0.0001$ relative to rimonabant. (D) Brain and plasma concentration of AM6545 and rimonabant 12 hours after dose administration, following daily i.p. dosage at $10 \mathrm{mg} / \mathrm{kg}$ for 28 days. Data represent mean \pm SEM from 3 mice per group. ${ }^{*} P<0.04$ relative to rimonabant. (E) Brain and plasma concentrations of AM6545 in Mdr1a/ $/ \mathrm{b}^{-/-}$and Mdr1a/ $/ \mathrm{b}^{-/-} \mathrm{Bcrp}{ }^{-/-}$mice and their wild-type (FVB) controls 1 hour after acute i.p. administration of $10 \mathrm{mg} / \mathrm{kg} \mathrm{AM6545.} \mathrm{Note} \mathrm{the}$ dramatic increase in brain levels of AM6545 in the knockout strains relative to wild-type controls. Data represent mean \pm SEM from 3 mice per group. ${ }^{\star} P<0.01$ relative to wild-type controls.

lar fluids, as compared with a ratio of 0.8 for rimonabant (Figure 1C). Brain and plasma levels were also measured 12 hours after dose administration, following chronic (28 days) treatment. The brain/plasma ratio of AM6545 remained low (i.e., 0.07), and the brain concentration of rimonabant continued to be much higher (approximately 14-fold) than that of AM6545 (Figure 1D).

In both cell-based and in vitro biochemical assays, AM6545 interacts at low micromolar concentrations with the $\mathrm{ABC}$ transporter P-glycoprotein (P-gp; Abcb1), which is localized on the luminal surface of capillary endothelial cells in the brain forming the blood- brain barrier (27) (Supplemental Figure 1; supplemental material available online with this article; doi:10.1172/JCI42551DS1). This suggests that transporter-mediated extrusion of AM6545 from the brain may contribute to its low apparent brain penetrance. This was further verified in P-gp-deficient $\left(M d r 1 a / b^{-/-}\right)$mice and in mice deficient in both P-gp and Bcrp/Abcg2, along with their wild-type controls. As shown in Figure 1E, brain penetrance of AM6545 increased dramatically in both knockout strains, resulting in brain/plasma ratios of 0.64 and 0.69 , respectively. This indicates that the low brain penetrance of AM6545 in wild-type mice 

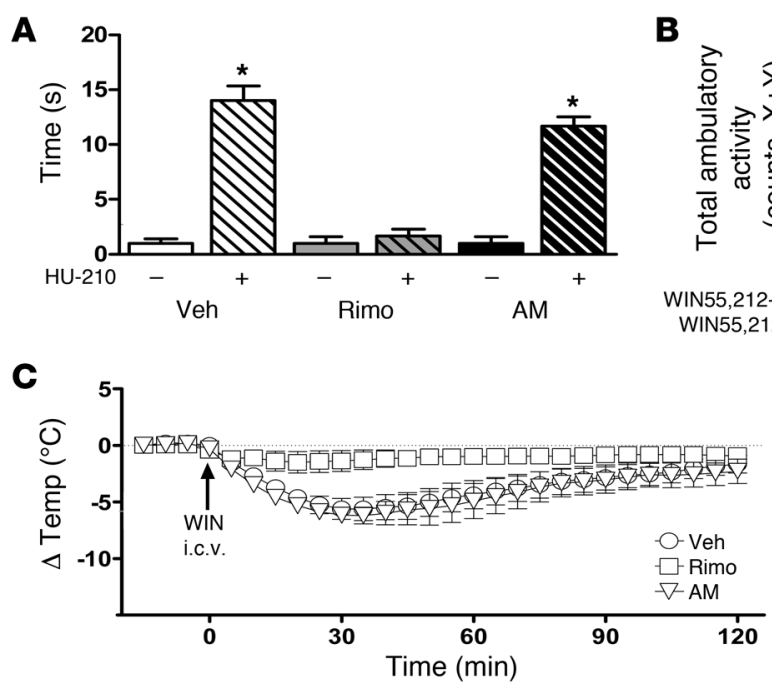

D

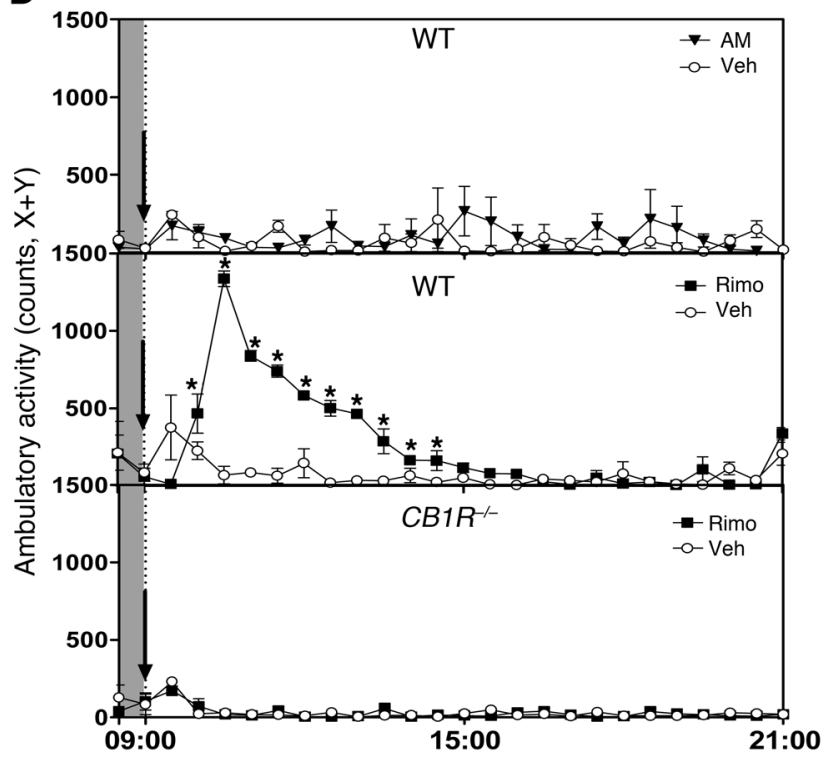

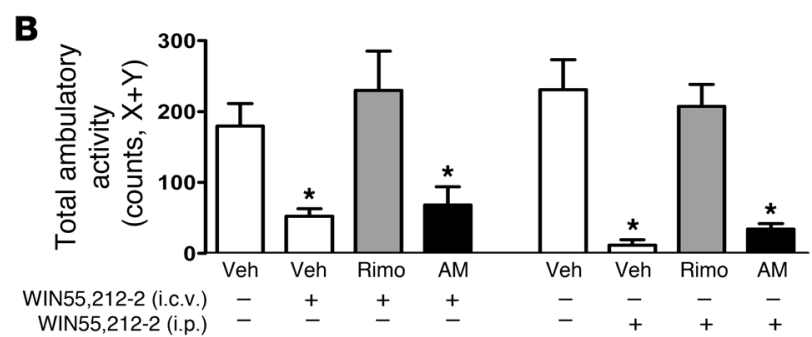

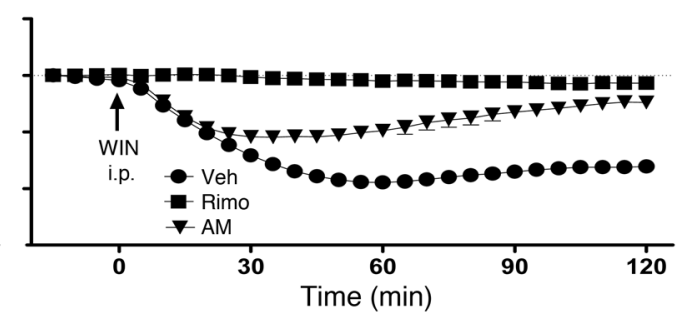

$\mathbf{E}$
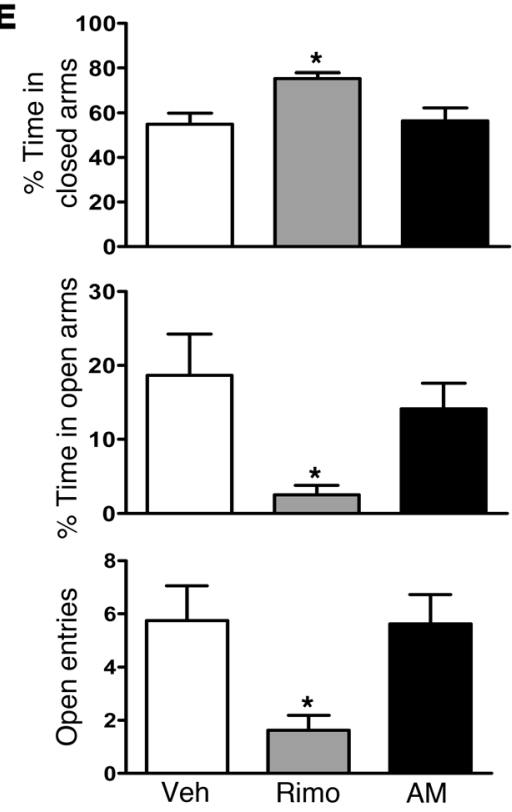

Figure 2

Behavioral activity profile of AM6545 and rimonabant. (A) Rimonabant, but not AM6545, inhibits HU-210-induced catalepsy, as measured by the bar assay. The antagonists (10 mg/kg, i.p.) were given 15 minutes prior to the i.p. injection of $30 \mu \mathrm{g} / \mathrm{kg} \mathrm{HU}-210$. Data represent mean $\pm \mathrm{SEM}$ from 5 mice per group. ${ }^{*} P<0.001$ relative to corresponding value in the absence of HU-210. (B) Rimonabant, but not AM6545, blocks hypomotility induced by WIN55,212-2 administered i.c.v. $(30 \mu \mathrm{g})$ or i.p. $(10 \mathrm{mg} / \mathrm{kg})$, as measured by disruption of infrared $x y$ beams. Data represent mean \pm SEM from 6-8 mice per group. ${ }^{*} P<0.009$ relative to corresponding vehicle (Veh) value. (C) Rimonabant (10 mg/kg, i.p.) blocks the hypothermic response to WIN55,212-2 administered either i.c.v. (30 $\mu \mathrm{g}$, left panel) or i.p. (10 mg/kg, right panel), whereas AM6545 (10 mg/kg, i.p.) does not affect the centrally induced response and partially inhibits the peripherally induced hypothermic response to WIN55,212-2. Data represent mean \pm SEM from 4-8 mice per group. Where error bars are absent, they are within the symbol. (D) Rimonabant, but not AM6545, increases ambulatory activity. Disruption of infrared $x y$ beams following administration of AM6545 (top) or rimonabant (middle) in wild-type mice or rimonabant in $C B 1 R^{--}$mice $\left(10 \mathrm{mg} / \mathrm{kg}\right.$, i.p. each, bottom). Data represent mean \pm SEM from $4-6$ mice per group. ${ }^{*} P<0.01$ relative to corresponding vehicle value. (E) Rimonabant, but not AM6545 (each at $10 \mathrm{mg} / \mathrm{kg}$, i.p.), has an anxiogenic effect in the EPM. Data represent mean \pm SEM from 8 mice per group. ${ }^{*} P<0.03$ relative to vehicle.

is due predominantly to active extrusion by P-gp. Furthermore, when tested in Caco-2 intestinal epithelial cell monolayers (28), AM6545 displays high permeability, with no evidence for active efflux (efflux ratio of 1.1). This suggests good oral bioavailability, also supported by similar plasma concentrations following i.p. and oral administration (Figure 1C).
AM6545 is inactive in behavioral paradigms. We next tested whether the reduced brain penetrance of AM6545 is associated with an attenuation of behavioral effects. Of the cannabinoid-induced behavioral tetrad (29), analgesia is known to have an important peripheral component (30). We therefore compared the effects of AM6545 and rimonabant in antagonizing cannabinoid-induced 

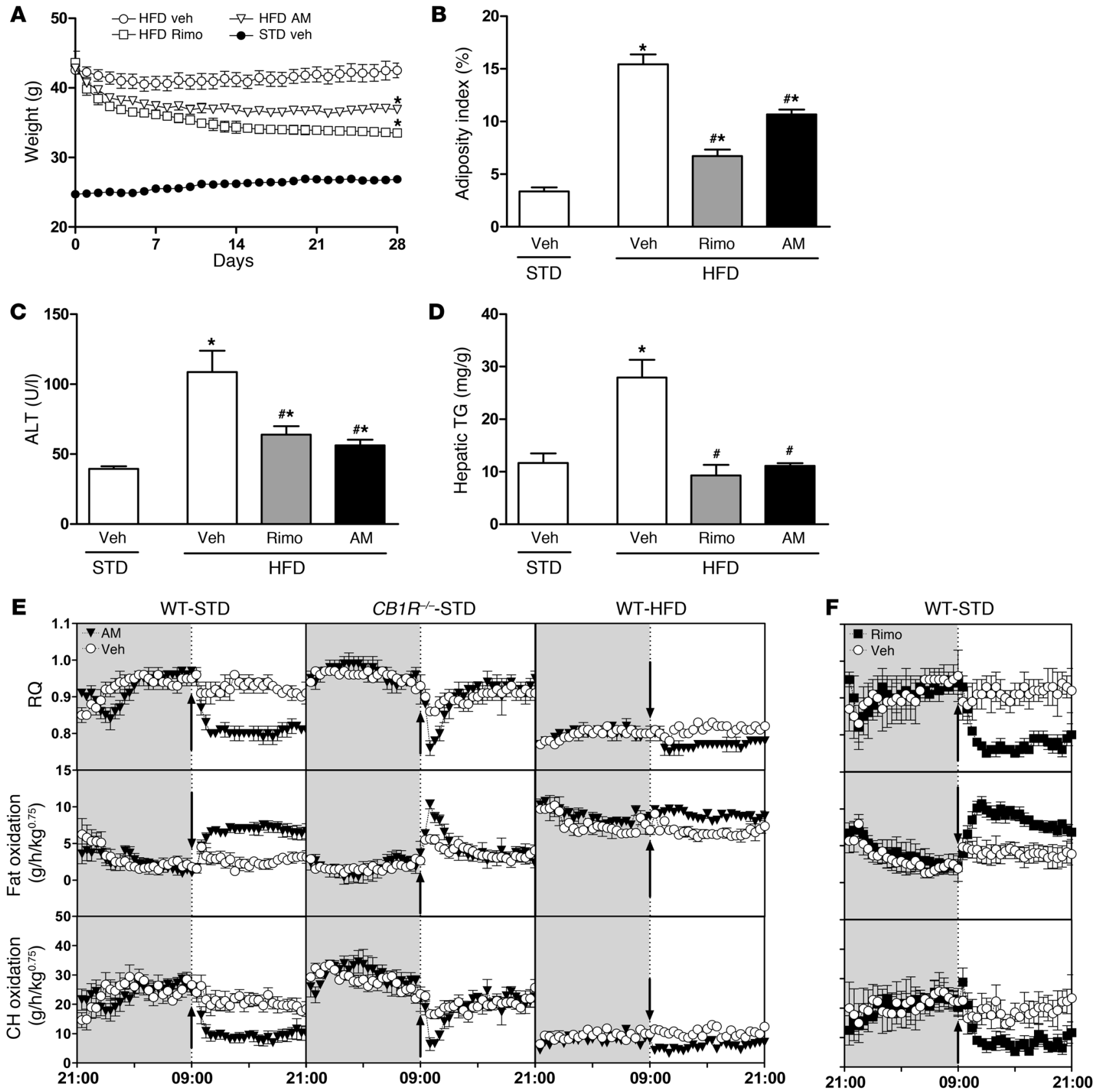

Figure 3

Metabolic effects of chronic treatment with AM6545 and rimonabant in DIO mice. Mice on STD or HFD for 14 weeks were treated with 10 $\mathrm{mg} / \mathrm{kg} / \mathrm{d}$, i.p., of either drug for 28 days. Note that both drugs reduced body weight (A), adiposity index (B), plasma ALT (C), and hepatic TG (D). Data represent mean \pm SEM from 8-12 mice per group from 3 experiments. ${ }^{*} P<0.0001$ relative to vehicle group on STD; ${ }^{*}<0.0001$ relative to vehicle group on HFD. (E) AM6545 induces $C_{B} B_{1}$-dependent reduction in $R Q$ by decreasing $C H O$ and increasing fat oxidation in wild-type mice on STD or on HFD. Indirect calorimetry over a 24-hour period: shaded area indicates lights off; arrows mark time of injection of vehicle (open symbols) or AM6545 (filled symbols). Note the absence of sustained effect of AM6545 in CB1 $R^{-/-}$mice on regular chow (middle panel). (F) Effects of rimonabant, $10 \mathrm{mg} / \mathrm{kg}$, i.p., on substrate utilization and $\mathrm{RQ}$ are similar to those of $A M 6545$. Data represent mean $\pm \mathrm{SEM}$ from 4 mice per group.

catalepsy, hypomotility, and hypothermia. Cannabinoid-induced catalepsy, quantified by the bar assay, is mediated exclusively by central $\mathrm{CB}_{1} \mathrm{R}$ (31). The marked increase in immobility induced in mice by the cannabinoid agonist HU-210 $(30 \mu \mathrm{g} / \mathrm{kg}$, i.p.) was completely blocked by rimonabant $(10 \mathrm{mg} / \mathrm{kg}$, i.p.) but was unaffected by a similar dose of AM6545 (Figure 2A). Similarly, rimonabant completely prevented the hypomotility induced by either i.p. or intracerebroventricular (i.c.v.) administration of the cannabinoid WIN55,212-2, whereas AM6545 at the same dose was without effect (Figure 2B). The hypothermic response to WIN55,212-2 was 

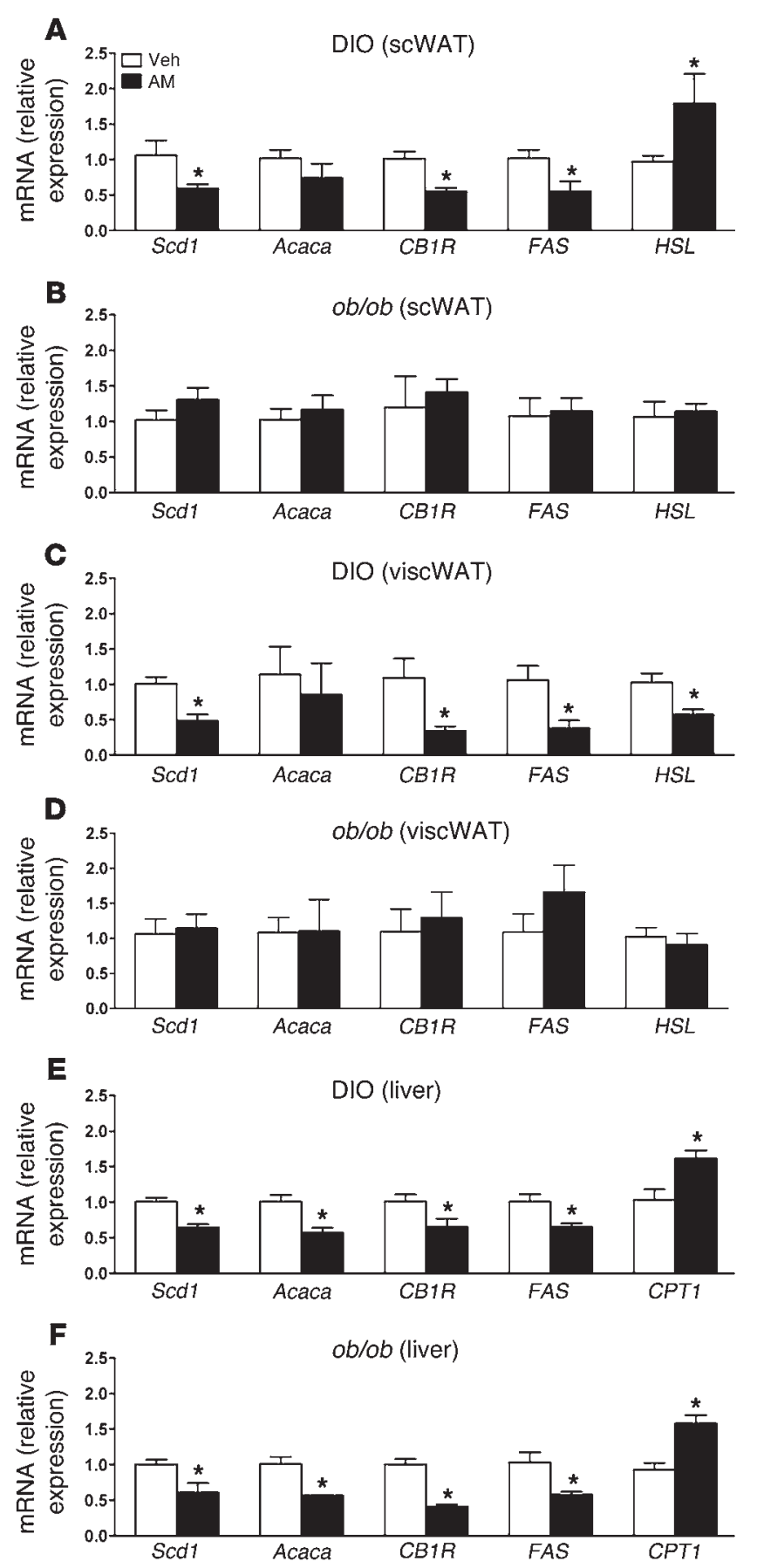

maximal following an i.c.v. dose of $30 \mu \mathrm{g}$ or an i.p. dose of $10 \mathrm{mg} /$ $\mathrm{kg}$. The response to the centrally administered agonist peaked at 30 minutes and returned to baseline within 2 hours, and it was completely blocked by pretreatment with $10 \mathrm{mg} / \mathrm{kg}$ rimonabant i.p. but was unaffected by the same dose of AM6545 (Figure 2C). The hypothermia was more profound after peripheral as compared with central administration of WIN55,212-2 and lasted up to 8 hours. This effect was again completely blocked by rimonabant, 10 $\mathrm{mg} / \mathrm{kg}$, i.p., and was partially inhibited by AM6545, with the residual response being similar in magnitude and duration to the control response to centrally administered WIN55,212-2 (Figure 2C).

\section{Figure 4}

Effect of AM6545 on subcutaneous (inguinal) and visceral (epididymal) white adipose tissue (scWAT and viscWAT) and liver mRNA expression of $C B 1 R$ and genes involved in lipid metabolism. (A, C, and E) DIO mice were on HFD for 14 weeks before treatment with $10 \mathrm{mg} / \mathrm{kg} / \mathrm{d}$, i.p., of AM6545 or vehicle for an additional 28 days. (B, D, and F) ob/ob mice on STD received the same daily dose of AM6545 for 28 days. Tissue samples were processed and mRNA levels were determined by real-time PCR as described in Methods. Data are mean \pm SEM from 4 mice per condition. ${ }^{*} P<0.05$ relative to vehicle group on HFD.

These findings suggest that both central and peripheral sites contribute to the hypothermic response to WIN55,212-2 and that AM6545 does not affect hypothermia mediated via central $\mathrm{CB}_{1} \mathrm{R}$.

Rimonabant, but not AM6545 (each at $10 \mathrm{mg} / \mathrm{kg}$, i.p.), also induced a marked and long-lasting increase in ambulatory activity in wild-type but not $\mathrm{CB} 1 \mathrm{R}^{-/-}$mice (Figure $2 \mathrm{D}$ ). Interestingly, when

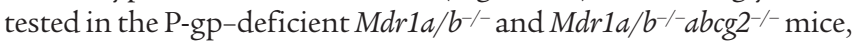
$10 \mathrm{mg} / \mathrm{kg}$ AM6545 caused a robust increase in ambulatory activity similar to rimonabant, reflecting its increased brain penetrance in these mice (Supplemental Figure 2). Similarly, rimonabant but not AM6545 (each at $10 \mathrm{mg} / \mathrm{kg}$, i.p.) induced a robust anxiogenic response in the elevated plus maze (EPM) paradigm (Figure 2E). Thus, AM6545 is devoid of the centrally mediated behavioral effects that are predictive of the neuropsychiatric side effects of brain-penetrant $\mathrm{CB}_{1} \mathrm{R}$ antagonists. In contrast, $10 \mathrm{mg} / \mathrm{kg}$ AM6545 completely blocked the anandamide-induced inhibition of upper gastrointestinal motility, an effect mediated by prejunctional $\mathrm{CB}_{1} \mathrm{R}$ in peripheral neurons innervating the gut (32) (Supplemental Figure 3). Because the dose of anandamide used $(10 \mathrm{mg} / \mathrm{kg}$, i.p.) was reported to be maximally effective in this paradigm (33), $\mathrm{CB}_{1} \mathrm{R}$ occupancy by AM 6545 can be assumed to be near maximal at the $10 \mathrm{mg} / \mathrm{kg}$ dose used in most of our experiments.

AM6545 improves the metabolic profile in mice with diet-induced obesity. The metabolic profile of AM6545 and rimonabant was next examined in mice with diet-induced obesity (DIO). Male C57BL/6J mice fed a high-fat diet (HFD) for 14 weeks became obese and were then started on daily i.p. injections of vehicle, rimonabant, or AM6545 (both at $10 \mathrm{mg} / \mathrm{kg} / \mathrm{d}$ ) for an additional 28 days. Age- and sex-matched mice on standard chow served as controls. The overweight and increased adiposity of mice on HFD were significantly reduced by both antagonists (Figure 3 , A and B). HFD-induced fatty liver, as reflected in elevated hepatic triglyceride (TG) content, and hepatocellular damage, as indicated by increased plasma ALT levels, were completely reversed by either rimonabant or AM6545 (Figure 3, C and D). Similar effects were observed after oral administration of AM6545 at 10 or $30 \mathrm{mg} / \mathrm{kg} / \mathrm{d}$ for 14 days (Supplemental Figure 4), indicating good oral bioavailability.

The effect of AM6545 on substrate utilization was analyzed by indirect calorimetry. In mice kept on standard chow, a bolus i.p. dose of $10 \mathrm{mg} / \mathrm{kg}$ AM6545 at the start of the light period caused a marked and sustained reduction in respiratory quotient (RQ), resulting from an increase in fat oxidation and decrease in carbohydrate oxidation (CHO) (Figure 3E), which were similar to the effects of rimonabant (Figure 3F). Only transient effects were seen in $\mathrm{CB}_{1 R^{-1}}$ mice (Figure 3E), indicating that the sustained changes were due to $\mathrm{CB}_{1} \mathrm{R}$ blockade. Similar effects of AM6545 were seen in mice on HFD, although they were smaller than in mice on standard diet, possibly due to the diet-induced decrease in basal levels of RQ and increase in fat oxidation (Figure 3E). Nevertheless, 

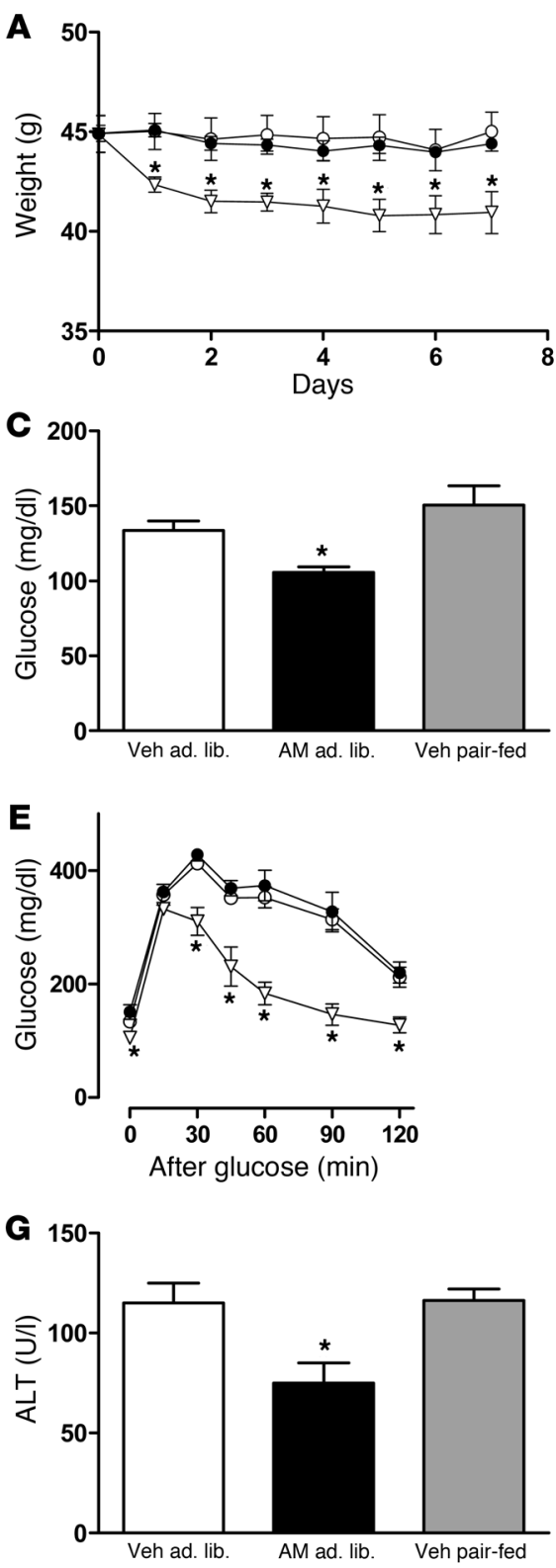
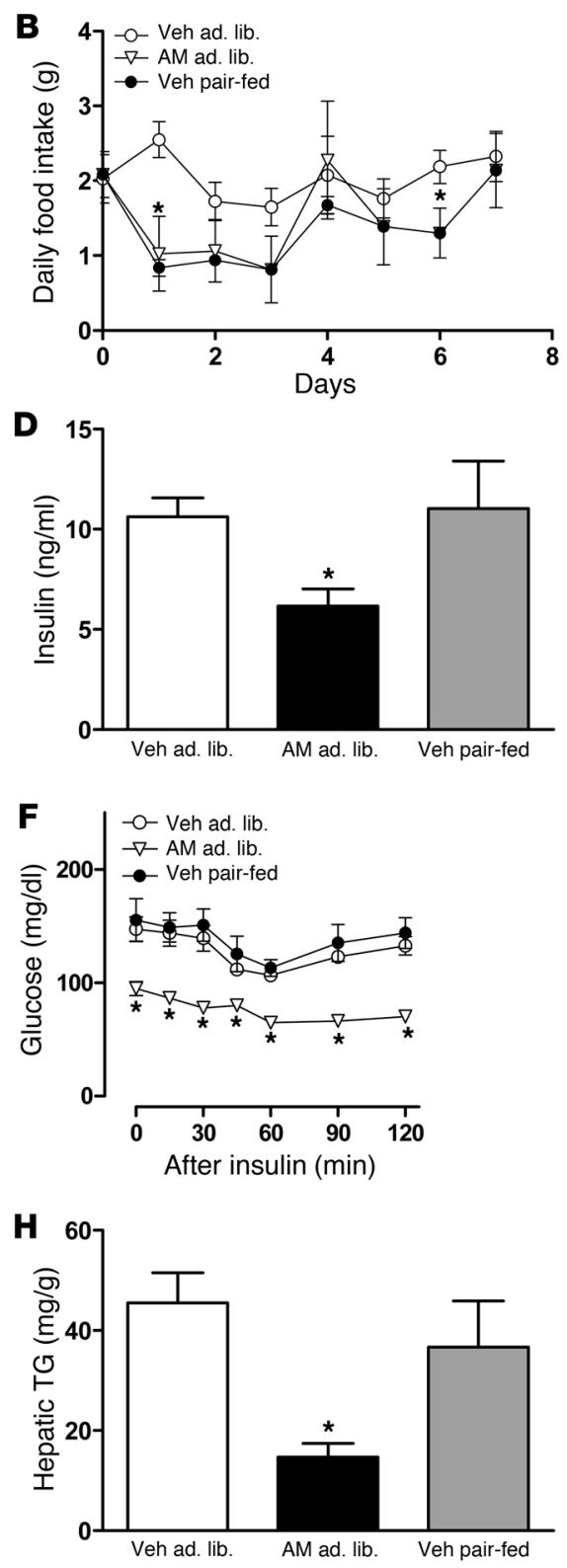

\section{Figure 5}

Metabolic effects of short-term treatment with AM6545 or pair feeding in DIO mice. Mice on HFD for 14 weeks were treated with AM6545 (10 mg/kg, i.p.) or vehicle for 7 days. Pair-fed mice were injected with vehicle and fed the same amount as consumed by the AM6545-treated animals over the preceding day. Note that food intake was inhibited only for a short time (B), and only AM6545 reduced body weight (A), blood glucose (C), insulin (D), serum ALT $(\mathbf{G})$, and hepatic TG $(\mathbf{H})$ levels and normalized the impaired glucose tolerance $(\mathbf{E})$ and insulin resistance $(\mathbf{F})$ relative to vehicle treatment under ad libitum (ad. lib.) conditions. Data are mean \pm SEM from 4 mice per condition. ${ }^{*} P<0.05$ relative to vehicle group on HFD. chronic (28 days) treatment of mice on HFD resulted in increased total energy expenditure in the case of both antagonists (Supplemental Figure 5). Thus, the modest decrease in body weight by AM6545 was probably due to increased lipid oxidation.

This is further indicated by the decreased gene expression of the lipogenic enzymes fatty acid synthase (FAS) and stearoyl coenzyme-A desaturase 1 ( $S c d 1)$ in both subcutaneous and visceral adipose tissue, whereas the expression of the lipolytic enzyme hormone-sensitive lipase (HSL) was increased in subcutaneous and decreased in visceral fat (Figure 4, A and C), similar to the reported effects of rimonabant (16). Decreased lipogenic and increased lipolytic gene expression was also evident in the liver of DIO mice, where AM6545 treatment resulted in decreased Scd1, FAS, and acetyl coenzyme A carboxylase-1 (Acaca) and increased carnitine palmitoyl transferase-1 (CPT1) expression (Figure 4E). In agreement with the reduced lipogenic gene expression, AM6545 blocked cannabinoid-induced de novo lipogenesis in vitro in iso- lated mouse hepatocytes (Supplemental Figure 6). AM6545 treatment also reduced $C B 1 R$ expression in both adipose tissue and liver (Figure 4, A, C, and E), which is again similar to recent findings with rimonabant (16).

The greater efficacy of rimonabant over AM6545 in reducing body weight is probably related to its additional ability to reduce total caloric intake (Supplemental Figure 7A). A smaller and more transient reduction in food intake by AM6545 did not affect total caloric intake over the treatment period (Supplemental Figure 7B). Nevertheless, to test whether the transient reduction in food intake may contribute to metabolic changes induced by short-term $\mathrm{CB}_{1}$ antagonist treatment, the effects of treating DIO mice with $10 \mathrm{mg} / \mathrm{kg} / \mathrm{d}$ AM6545 for 7 days were compared with the effects of pair feeding. As illustrated in Figure 5, short-term AM6545 treatment caused significant reductions in caloric intake, body weight, blood glucose and insulin levels, serum ALT, and hepatic TG content; normalized the impaired glucose tolerance; and improved insulin sensitivity relative 


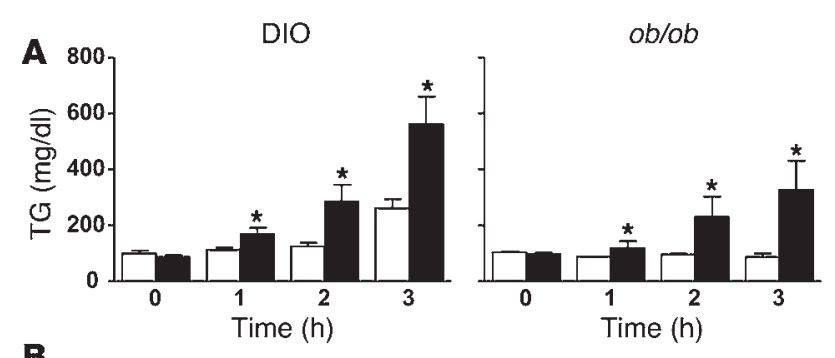

B

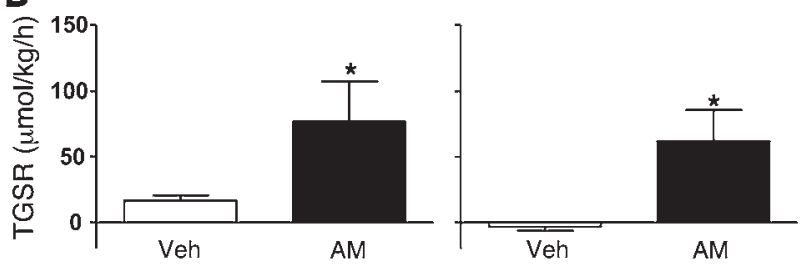

to that in free-feeding, vehicle-treated mice. In the pair-fed group, food intake was held at the same reduced level as in AM6545-treated mice, yet all other parameters were similar to those in vehicle-treated controls. Thus, the transient reduction of caloric intake by AM 6545 does not contribute to its metabolic effects.

In addition to reducing hepatic lipogenesis and increasing fatty acid oxidation, AM6545 treatment also resulted in a marked increase in the hepatic production and release of TG-rich VLDL, as measured in tyloxapol-treated DIO mice (Figure 6). All of these effects could contribute to the reduction of hepatic steatosis.

A key component of the obesity-related metabolic syndrome is insulin resistance, which manifested in the simultaneous presence of hyperglycemia and hyperinsulinemia (Figure 7, A and B). DIO mice also displayed hyperleptinemia (Figure 7C), an indication of leptin resistance, whereas the plasma level of adiponectin, an adipokine that promotes fatty acid oxidation, was reduced (Figure 7D). All of these changes were attenuated or completely reversed by $\mathrm{CB}_{1} \mathrm{R}$ blockade, rimonabant being somewhat more efficacious than AM6545. DIO mice also displayed reduced glucose tolerance (Figure 7E) and moderately decreased sensitivity to the hypoglycemic effect of insulin (Figure 7F). The reduced glucose tolerance, reflected by the increase in AUC from $327 \pm 24$ to $437 \pm 14 \mathrm{mg} / \mathrm{dl} / \mathrm{h}$ $(P<0.01)$ according to the i.p. glucose tolerance test, was reversed to control levels by chronic treatment with either rimonabant (AUC, $279 \pm 35 \mathrm{mg} / \mathrm{dl} / \mathrm{h}$ ) or AM6545 (358 $\pm 14 \mathrm{mg} / \mathrm{dl} / \mathrm{h})$. Insulin resistance, as assessed from the insulin-induced change in the normalized blood glucose values, was increased by the HFD, and this increase was reversed by rimonabant but not by AM6545 treatment of DIO mice. When insulin resistance was assessed by the homeostasis model assessment-insulin resistance (HOMA-IR) method and the insulin sensitivity index, both antagonists significantly improved insulin sensitivity, but the effect of rimonabant was stronger (Supplemental Figure 8).

Weight-independent metabolic effects of AM6545 in leptin-deficient obese mice. In order to test whether peripheral $\mathrm{CB}_{1} \mathrm{R}$ blockade affects metabolic parameters in more than one model of obesity, we used genetically leptin-deficient $o b / o b$ mice that develop extreme obesity associated with diabetes, fatty liver, and dyslipidemias. Treatment end points were determined at 7 as well as at 28 days to gain insight into the time course of their development. Daily treatment of adult male $o b / o b$ mice for 7 days with $10 \mathrm{mg} / \mathrm{kg}$ of either AM6545 or rimonabant had no significant effect on body weight

\section{Figure 6}

VLDL-TG secretion rates in DIO and ob/ob mice. Adult DIO and ob/ob mice were treated with $10 \mathrm{mg} / \mathrm{kg} / \mathrm{d}$, i.p., of AM6545 or vehicle for 7 days. TGSRs were determined under fasting conditions from the plasma TG versus time curve after the injection of Triton WR-1339, as described in Methods. (A) Plasma TG accumulation over time after Triton WR-1339 administration (500 mg/kg, i.p.) (B) AM6545-induced increase in TGSR $(\mu \mathrm{mol} / \mathrm{kg} / \mathrm{h})$ in DIO and ob/ob mice. Data are mean \pm SEM from 6 mice per group. ${ }^{\star} P<0.05$ relative to corresponding vehicle value.

and adiposity index (Figure 8A), yet both antagonists significantly improved glucose tolerance and insulin resistance (Figure 8B) and reduced the elevated levels of plasma glucose and insulin, with AM6545 being somewhat more effective than rimonabant (Figure 8C). AM6545, but not rimonabant, also markedly lowered liver TG content and reduced hepatocellular damage, as reflected by the lowering of plasma levels of ALT (Figure 8D), whereas after 28 days of treatment, both antagonists were effective in reducing hepatic TG content (Supplemental Figure 9C). AM6545, but not rimonabant, increased HDL cholesterol, and both antagonists reduced LDL cholesterol levels. Plasma TG markedly increased after 7 days of treatment with AM6545, probably as a result of the rapid and robust clearance of liver TGs (Figure 8E). Indeed, AM6545 treatment caused an increase in VLDL-TG production in $o b / o b$ mice similar to that observed in DIO mice (Figure 6).

In $o b / o b$ mice treated for 28 days, rimonabant, but not AM6545, caused a modest but significant reduction in body weight and adiposity, and both compounds improved dyslipidemia by reducing plasma TGs and LDL cholesterol levels and increasing plasma HDL cholesterol (Supplemental Figures 9 and 10).

AM6545 treatment improves leptin sensitivity. The ability of AM6545 treatment to reduce body weight and adiposity in DIO mice but not in leptin-deficient $o b / o b$ mice suggests that AM6545 treatment may sensitize adipose tissue to the lipolytic effects of endogenous leptin. Indeed, the AM6545-induced changes in lipogenic gene expression were completely absent in both subcutaneous and visceral adipose tissue of similarly treated $o b / o b$ mice (Figure 4, B and D). In contrast to adipose tissue, lipogenic gene expression in the liver was similarly reduced by AM6545 in DIO and $o b / o b$ mice (Figure 4, E and F). AM6545 also reversed the HFD-induced loss of the appetite-suppressing effect of leptin (Supplemental Figure 11).

Blockade of hepatic $C B_{1} R$ improves glucose tolerance and reduces hepatic $T G$ s. Selective deletion of $\mathrm{CB}_{1} \mathrm{R}$ in hepatocytes has been shown to protect mice from HFD-induced glucose intolerance and insulin resistance and to attenuate the associated steatosis, which implicates endocannabinoids acting via hepatic $\mathrm{CB}_{1} \mathrm{R}$ in these processes (24). We generated mice transgenically expressing $\mathrm{CB}_{1} \mathrm{R}$ in hepatocytes on a global $\mathrm{CB}_{1} \mathrm{R}-\mathrm{knockout}$ and $\mathrm{C} 57 \mathrm{BL} / 6 \mathrm{~J}$ background ( $h \mathrm{tgCB} 1 R^{-/-}$mice) by injecting a DNA construct containing the mouse albumin promoter and the $\mathrm{CB}_{1} \mathrm{R}$ coding region into homozygous $C B 1 R^{-/-}$oocytes from superovulated donors. $C B 1 R^{-/-}$ mice heterozygous for the transgene and their $C B 1 R^{-/-}$littermates 

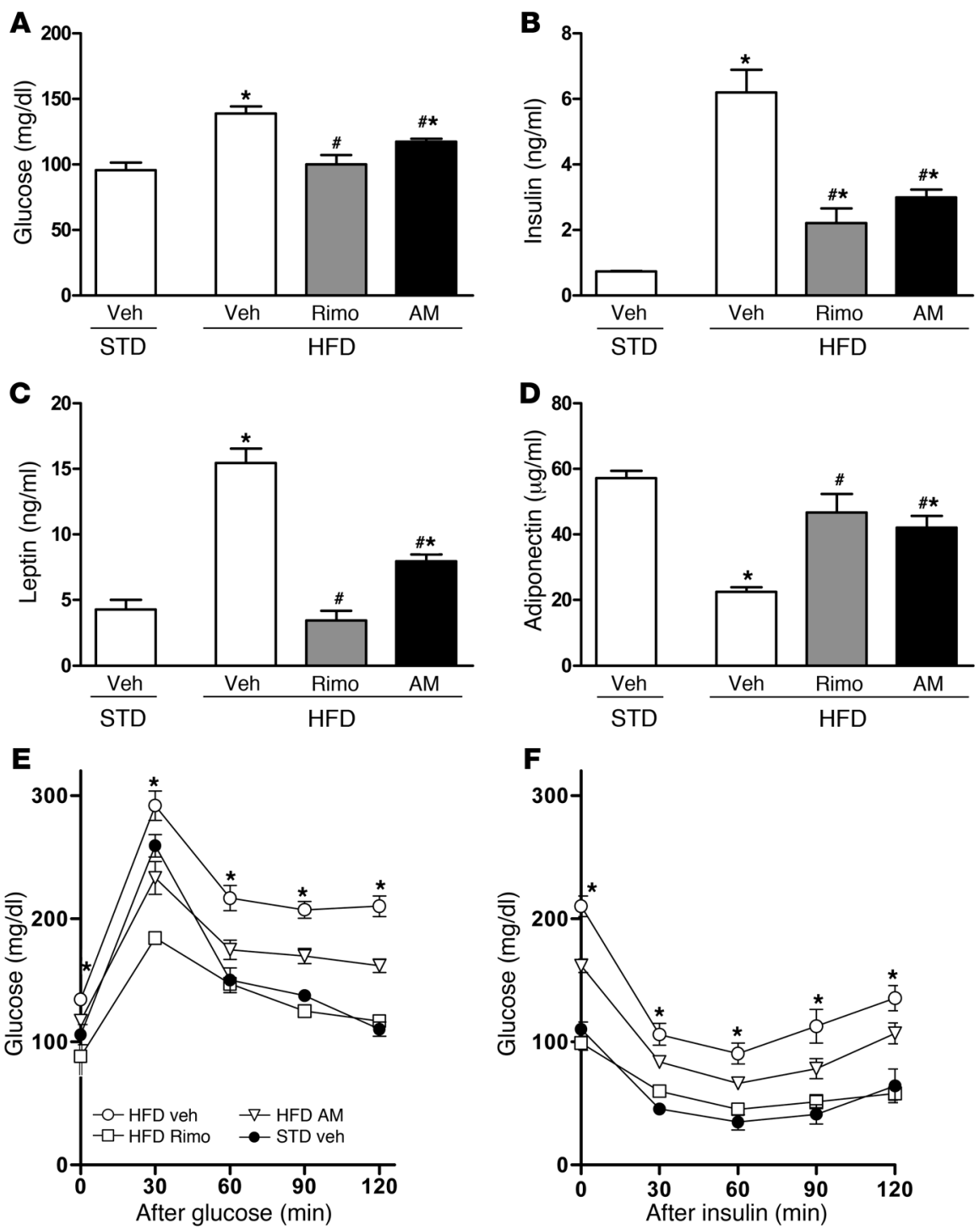

\section{Figure 7}

Effects of rimonabant and AM6545 on the hormonal control of carbohydrate metabolism in mice with DIO. Both rimonabant and AM6545 (10 mg/kg/d, i.p., for 28 days) counteract HFD-induced increases in plasma glucose (A), insulin (B), and leptin (C) and decreases in adiponectin levels (D), and improve diet-induced glucose intolerance (E) and insulin resistance (F). Mice were fed STD or HFD ( $60 \%$ of calories from fat) for 14 weeks. Glucose tolerance was tested following the i.p. injection of $2 \mathrm{~g} / \mathrm{kg}$ glucose. After 2 hours, the mice received $0.75 \mathrm{mU} / \mathrm{g}$ insulin i.p. Data represent mean \pm SEM from 8-12 mice per group. ${ }^{*} P<0.0001$ relative to vehicle group on STD; $\# P<0.001$ relative to vehicle group on HFD. were used to test whether activation of hepatic $\mathrm{CB}_{1} \mathrm{R}$ is sufficient to induce diet-induced glucose intolerance/insulin resistance and hepatic steatosis and whether their blockade may contribute to the improved glucose tolerance following short-term treatment with a peripheral $\mathrm{CB}_{1} \mathrm{R}$ antagonist. $h \operatorname{tg} C B 1 R^{-/-}$mice were viable and displayed no gross defects or obvious functional abnormalities. Similar to their global $C B 1 R^{-/-}$littermates, they did not express $\mathrm{CB}_{1} \mathrm{R}$ in extrahepatic tissues, including the brain, but had both $C B 1 R$ mRNA and protein present in hepatocytes at levels somewhat higher than those in wild-type C57BL/6J mice (Figure 9A). Exposure of $h \operatorname{tg} C B 1 R^{-/-}$mice to HFD resulted in a much smaller, though significant, elevation of hepatic TG levels relative to those of wild-type mice on HFD, whereas no such change was observed in their $C B 1 R^{-/-}$littermates (Figure 9B). In contrast, the robust HFD-induced glucose intolerance and reduced insulin sensitivity in $b t g C B 1 R^{-/}$mice (Figure 9C) were similar to those reported earlier in wild-type mice, as opposed to $C B 1 R^{-/-}$mice, which remain insulin sensitive (34). HFD also resulted in the activation of the ER stress response in the liver as indicated by increased phosphorylation of eukaryotic translation initiation factor $2 \alpha$ (eIF2 $\alpha$ )
(Figure 9D), a process that has been linked to insulin resistance (35). Furthermore, daily treatment of $h \operatorname{tgCB} 1 R^{-/-}$mice on HFD for 7 days with $10 \mathrm{mg} / \mathrm{kg}$ AM6545, but not with vehicle, reversed all the above diet-induced changes (Figure 9).

\section{Discussion}

Here we have demonstrated that treatment of obese mice with a peripherally restricted $\mathrm{CB}_{1} \mathrm{R}$ antagonist improves glycemic control and dyslipidemia and reverses hepatic steatosis, which strongly supports the contribution of peripheral $\mathrm{CB}_{1} \mathrm{R}$ activation to these hormonal/metabolic abnormalities. In the absence of any change in body weight in $o b / o b$ mice treated with AM6545, the observed improvements in metabolic parameters were clearly weight independent. In mice with DIO, AM6545 did reduce body weight, but it was less efficacious than the brain-penetrant $\mathrm{CB}_{1} \mathrm{R}$ antagonist rimonabant. This is in agreement with the widely held notion that weight reduction by global $\mathrm{CB}_{1} \mathrm{R}$ blockade is the combined result of a centrally mediated decrease in caloric intake and a peripherally mediated increase in energy expenditure $(11,36)$. Indeed, rimonabant, but not AM6545, reduced total caloric intake dur- 

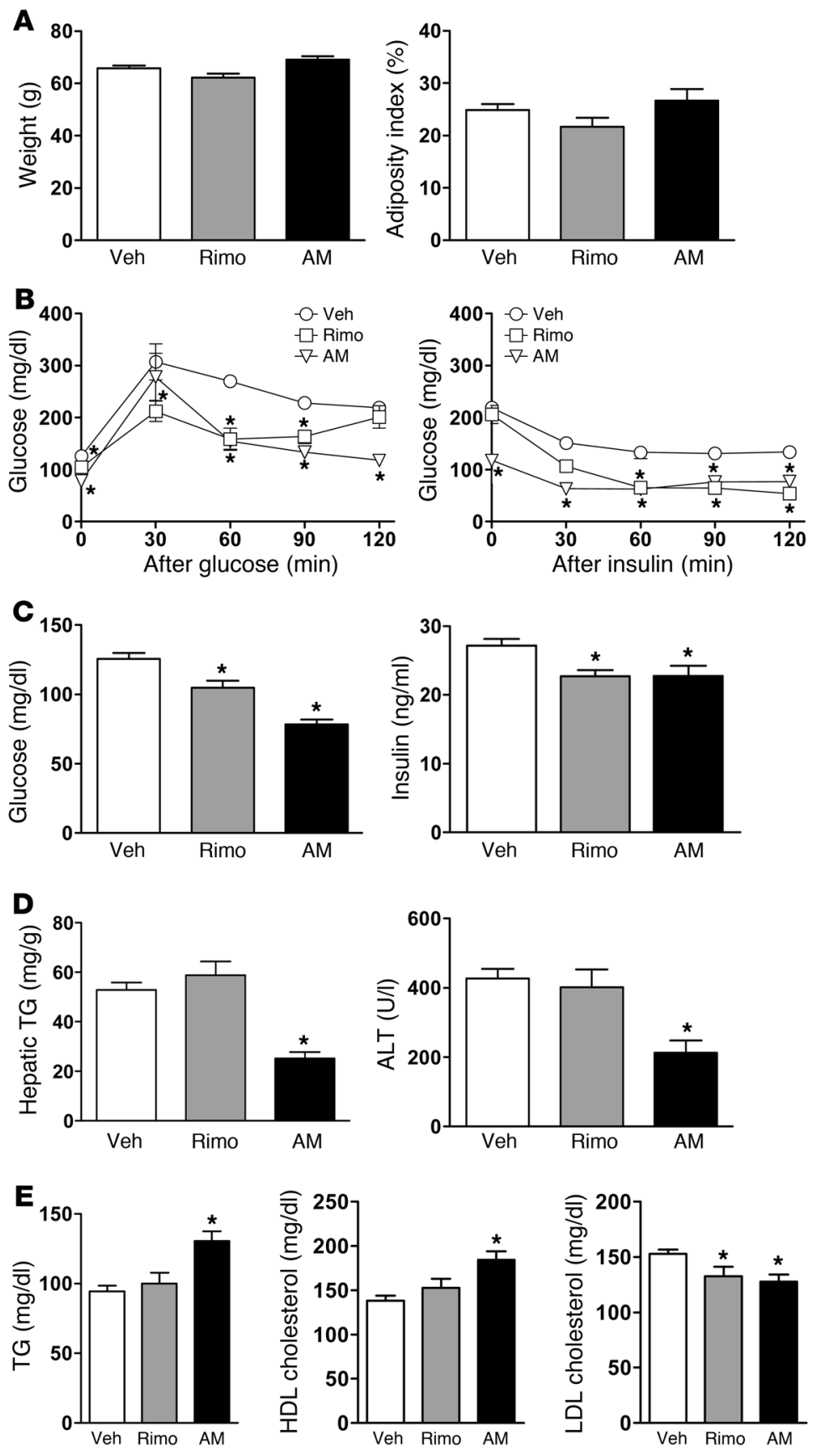

\section{Figure 8}

Effects of short-term $\mathrm{CB}_{1} \mathrm{R}$ blockade on hormonal and metabolic parameters in ob/ob mice. Treatment of ob/ob mice with $10 \mathrm{mg} / \mathrm{kg} / \mathrm{d}$, i.p., of rimonabant or AM6545 for 7 days does not affect body weight and adiposity (A), but improves glucose tolerance and insulin resistance (B) and reduces plasma glucose and insulin levels (C). AM6545, but not rimonabant, reduces liver TG content and plasma ALT levels (D). Effects of rimonabant and AM6545 on plasma TG and on HDL and LDL cholesterol levels (E). Data represent mean \pm SEM from 6 mice per group. ${ }^{*} P<0.05$ relative to corresponding vehicle value.

contribute to the alleviation of hepatic insulin resistance (38). Blocking adipocyte $\mathrm{CB}_{1} \mathrm{R}$ may also directly inhibit lipogenesis by decreasing the gene expression of the lipogenic enzymes Scd1 and FAS in adipose tissue of AM6545-treated DIO mice (Figure 4, A and C). Interestingly, AM6545 increased HSL expression in subcutaneous fat but decreased it in visceral fat, similar to the reported effects of rimonabant in DIO mice (16). Although we found that the reduction in adipose tissue mass by AM6545 was similar in the two types of fat tissue (data not shown), the differential regulation of HSL expression may reflect qualitative differences in the effects of endocannabinoids on subcutaneous and visceral adipose tissue.

A possible alternative target of AM6545 in adipose tissue is presynaptic $\mathrm{CB}_{1} \mathrm{R}$ on sympathetic nerve terminals, stimulation of which will inhibit norepinephrine release (39). Adipocytes produce and secrete endocannabinoids (40) that could tonically activate such receptors. Rimonabant has been shown to increase norepinephrine turnover in peripheral tissues of wild-type mice but not mice that lack $\mathrm{CB}_{1} \mathrm{R}$ in forebrain and sympathetic neurons (41), which makes the above mechanism plausible. The role of such presynaptic $C_{1} R$ is compatible with recent findings that hypothalamic leptin suppresses anandamide in white adipose tissue, and when this suppression of endocannabinoid tone is prevented by systemic $\mathrm{CB}_{1} \mathrm{R}$ activation or by sympathetic denervation of fat pads, leptin fails to suppress adipose tissue lipogenesis (42). Regardless of the specific cellular target of $\mathrm{CB}_{1} \mathrm{R}$ antagonists in adipose tissue, the above-described effects of AM6545 reinforce recent indirect evidence for a partially peripheral mechanism for the reduction of body weight and adiposity by brain-penetrant $\mathrm{CB}_{1} \mathrm{R}$

ing the 4-week treatment period, most likely through blockade of $\mathrm{CB}_{1} \mathrm{R}$ in the brain (37), and selective blockade of peripheral $\mathrm{CB}_{1} \mathrm{R}$ by AM6545 in DIO mice was associated with increased total energy expenditure due to increased fat burning (Figure 3E and Supplemental Figure 5). These metabolic effects of AM6545 were fully evident as early as after 7 days of treatment and were not replicated by pair feeding (Figure 5), which rules out the role of the transient reduction in food intake by AM6545 as their cause.

A likely target of $\mathrm{AM} 6545$ is $\mathrm{CB}_{1} \mathrm{R}$ in adipocytes, blockade of which results in increased adiponectin secretion (23). AM6545 treatment reversed the diet-induced suppression of plasma adiponectin (Figure 7D), which probably contributed to the observed increase in fat oxidation. The rise in adiponectin could also antagonists $(11,26,43,44)$.

The differential effectiveness of AM6545 in reducing body weight and adiposity in DIO mice but not in $o b / o b$ mice may be related to leptin. DIO is known to trigger a primarily peripheral form of leptin resistance $(45,46)$, which is reflected in a compensatory increase in plasma leptin levels $(6,15)$. In turn, the observed reversal of hyperleptinemia by $\mathrm{CB}_{1} \mathrm{R}$ antagonists reflects improved leptin sensitivity, analogous to the enhanced leptin sensitivity of $C B 1 R^{-/-}$mice (47). In agreement with the above reports, we found that the acute anorexigenic effect of leptin is reduced in mice on HFD, and this reduction was reversed following daily treatment with AM6545 for 9 days (Supplemental Figure 11). Leptin is known to promote fatty acid oxidation independently of its effects 


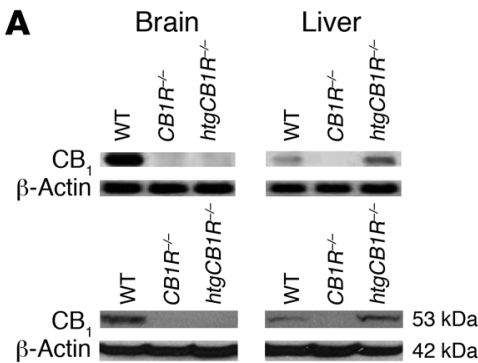

B
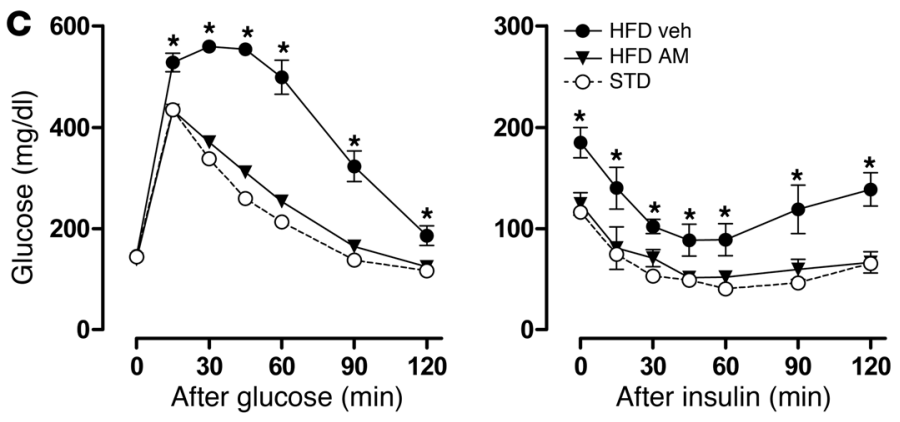

D

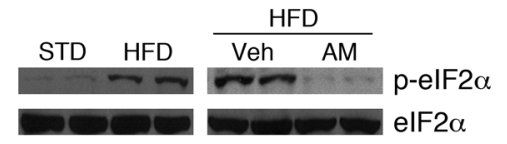

Figure 9

Blockade of hepatic $\mathrm{CB}_{1} \mathrm{R}$ by $\mathrm{AM} 6545$ reverses diet-induced insulin resistance. (A) $\mathrm{CB}_{1} \mathrm{R}$ expression in $h$ tg $C B 1 R^{-/-}$mice is limited to hepatocytes. $C B 1 R$ mRNA (top) and protein (bottom) are visualized by RT-PCR and Western blotting, respectively, in brain and liver tissue from wild-type, $C B 1 R^{-1-}$, and $h \operatorname{tgCB1} R^{-1-}$ mice. For details, see Methods. (B) Chronic treatment with AM6545 (10 mg/kg/d for 7 days) reduces hepatic TG in wild-type and $h t g C B 1 R^{-/-}$but not in $C B 1 R^{-/-}$mice on HFD. Data represent mean \pm SEM from 6 mice per group. ${ }^{*} P<0.05$ compared with corresponding vehicle value; ${ }^{\dagger} P<0.05$ compared with corresponding value in $C B 1 R^{-/-}$mice. (C) $h t g C B 1 R^{-1-}$ mice were kept on STD or HFD for 20 weeks. Mice were then treated with vehicle or AM6545 (10 mg/kg, i.p.) for 7 days and, after overnight fasting, were subjected to an ipGTT (left) followed by ipITT (right). ${ }^{*} P<0.05$ compared with corresponding values in vehicle-treated, STD-fed mice. Note the marked glucose intolerance of vehicle-treated mice on HFD relative to both AM6545-treated mice on HFD or the control group on STD (AUC, $426 \pm 19$ versus $156 \pm 6$ or $165 \pm 47$, respectively, $n=6,{ }^{\star} P<0.05$ ). Data represent mean \pm SEM from 6 mice per group. (D) Blockade of hepatic $\mathrm{CB}_{1} \mathrm{R}$ reverses the HFDinduced ER stress response, as indicated by the phosphorylation state of elF2 $\alpha$.

on food intake through activation of AMP kinase in muscle and adipose tissue (48). This parallels the ability of $\mathrm{CB}_{1} \mathrm{R}$ antagonists to increase the activity of the mitochondrial fatty acid oxidative pathway in liver (24) and increased mitochondrial biogenesis in white adipose tissue (49). Thus, sensitization to the metabolic actions of endogenous leptin may contribute to the increase in fat oxidation and secondary weight loss following AM6545 treatment in DIO mice but not in leptin-deficient $o b / o b$ mice. Direct evidence for such a mechanism is provided by the present findings that, in contrast to its effects in DIO mice, AM6545 treatment failed to decrease lipogenic and increase lipolytic gene expression in adipose tissue of $o b / o b$ mice (Figure 4, B and D).

Apart from showing a small increase in hepatic TGs, $h \mathrm{tg} C B 1 R^{-/-}$ mice were largely resistant to HFD-induced steatosis (Figure 9B). Together with earlier findings that indicate partial protection of liver-specific $C B 1 R^{-/-}$mice from HFD-induced steatosis (24), this points to a dominant role for extrahepatic $C_{1} R$ in the development of diet-induced fatty liver. Adipose tissue is a likely candidate, as it may provide free fatty acids for hepatic TG synthesis (16). However, the essentially complete and rapid reversal of hepatic steatosis by AM6545, which indicates a dominant role for peripheral $C_{1} R$, may not be due to a simple reversal of the processes that led to its development. Hepatic $\mathrm{CB}_{1}$ Rs are likely involved, as indicated by the AM6545-induced marked increase in TG-rich VLDL secretion, which paralleled the rapid and near complete elimination of excess hepatic TGs. Preferential targeting of hepatic $\mathrm{CB}_{1} \mathrm{R}$ was further facilitated by the accumulation of AM6545 in the liver (Figure 1C). In a recent study, treatment of mice with a novel inhibitor of monoglyceride lipase caused an acute increase in hepatic levels of the endocannabinoid 2-arachidonoylglycerol (2-AG) accompanied by a $\mathrm{CB}_{1} \mathrm{R}$-mediated increase in plasma TGs. This was due to reduced TG clearance with no change in TG secretion by either $\mathrm{CB}_{1} \mathrm{R}$ agonist or antagonist (25), which is different from the present findings. It is possible, however, that the link between $\mathrm{CB}_{1} \mathrm{R}$ and $\mathrm{TG}$ secretion requires long-term activation of the hepatic endocannabinoid system, as induced by HFD. The latter, unlike the acute model, is associated with steatosis, upregulation of hepatic $\mathrm{CB}_{1} \mathrm{R}(15,16)$, and elevated hepatic anandamide rather than 2-AG levels (15).

At the $10 \mathrm{mg} / \mathrm{kg}$ dose of AM6545 used here, $\mathrm{CB}_{1} \mathrm{R}$ occupancy is near maximal, given that the plasma concentration of the drug (approximately $3 \mu \mathrm{M}$, Figure 1C) exceeded its $K_{I}$ by 3 orders of magnitude. A further indication that blockade of peripheral $\mathrm{CB}_{1} \mathrm{R}$ is near complete at this dose is that AM6545 completely blocked inhibition of gut motility by a dose of anandamide $(10 \mathrm{mg} / \mathrm{kg}$, Supplemental Figure 3) previously shown to be maximally effective in this paradigm (33). Furthermore, no additional reduction of hepatic TGs and tissue damage markers was observed when the dose of AM6545 was increased from 10 to $30 \mathrm{mg} / \mathrm{kg}$ (Supplemental Figure 4). The observed absence of behavioral effects is 
therefore noteworthy, as it suggests that the therapeutic efficacy of AM6545 could be maximized without the risk of neuropsychiatric side effects. In recent clinical trials with brain-penetrant $C_{1} R$ antagonists, concern about neuropsychiatric side effects limited the daily dose used to levels that resulted in only partial (approximately $30 \%)$ occupancy of $\mathrm{CB}_{1} \mathrm{R}(8-11,50)$, which may have limited their therapeutic efficacy.

Both rimonabant and AM6545 were effective in attenuating obesity-related glucose intolerance and insulin resistance and normalizing the elevated blood glucose and insulin levels. Although in DIO mice, rimonabant was more efficacious than AM6545 in this regard, in $o b / o b$ mice AM6545 was as effective as rimonabant, suggesting that the improved glycemic control is primarily due to blockade of peripheral $\mathrm{CB}_{1} \mathrm{R}$. A similar conclusion is supported by the finding that insulin sensitivity is improved in DIO rats by chronic systemic, but not by i.c.v., administration of rimonabant, even though the two types of treatment had similar effects on food intake (26). $\mathrm{CB}_{1} \mathrm{R}$ on hepatocytes is one of the targets of AM6545. Hepatic $\mathrm{CB}_{1}$ Rs play an important role in insulin resistance, as mice with either global or hepatocytespecific knockout of $\mathrm{CB}_{1} \mathrm{R}$ remain insulin sensitive on $\mathrm{HFD}(24)$. The present findings using a rescue model in which $\mathrm{CB}_{1}$ Rs are expressed only in hepatocytes indicate that hepatic $\mathrm{CB}_{1} \mathrm{Rs}$ are not only necessary, but sufficient to account for the diet-induced glucose intolerance and insulin resistance. When kept on HFD, these transgenic mice develop glucose intolerance and moderate insulin resistance, whereas their global $\mathrm{CB}_{1} \mathrm{R}-\mathrm{knockout}$ littermates are resistant to these diet-induced changes. Furthermore, AM6545 treatment normalizes glycemic control in the transgenic mice, which directly implicates $\mathrm{CB}_{1} \mathrm{R}$ on hepatocytes as a peripheral target for AM6545. Indeed, our recent experiments using euglycemic-hyperinsulinemic clamp indicate that hepatic $\mathrm{CB}_{1} \mathrm{Rs}$ play a dominant role in HFD-induced hepatic insulin resistance by increasing hepatic glucose production and inhibiting the antigluconeogenic effect of insulin (J. Liu et al., unpublished observations). The possible additional contribution of $\mathrm{CB}_{1} \mathrm{R}$ in skeletal muscle, adipose tissue, and pancreatic $\beta$-cells to the effects of AM6545 on glycemic control remains to be explored.

In summary, AM6545 is a novel, peripherally restricted $\mathrm{CB}_{1} \mathrm{R}$ antagonist with nanomolar affinity, selectivity for $\mathrm{CB}_{1} \mathrm{R}$, and therapeutically relevant efficacy in reducing weight and improving hormonal/metabolic abnormalities in animal models of obesity. The previously published, peripherally restricted compound URB447 has approximately 100 times lower $\mathrm{CB}_{1} \mathrm{R}$ affinity $\left(\mathrm{IC}_{50}, 313 \mathrm{nM}\right)$ and lacks $\mathrm{CB}_{1} / \mathrm{CB}_{2}$ selectivity (51), and another recently published compound with reduced brain penetrance has similarly low $\mathrm{CB}_{1} \mathrm{R}$ affinity (159 $\mathrm{nM})$ (52). An article describing another peripherally restricted $C_{1} R$ antagonist with nanomolar potency and a high degree of selectivity for $\mathrm{CB}_{1}$ over $\mathrm{CB}_{2}$ receptors appeared after the present study had been submitted for publication. This antagonist was found to reduce body weight in obese rodents and to inhibit cannabinoid-induced hypothermia only at a high dose, but its metabolic and behavioral profile remains to be established (53).

The absence of neurobehavioral effects of AM6545 similar to those observed with rimonabant suggests that AM6545 will have fewer neuropsychiatric side effects in humans. As a neutral $\mathrm{CB}_{1} \mathrm{R}$ antagonist, AM6545 is also expected to cause less nausea than inverse $C_{1} R$ agonists do (54). Therefore, further testing and development of compounds of this class may be warranted for the pharmacotherapy of the metabolic syndrome.

\section{Methods}

Synthetic procedures and compound characterization. 5-(4-[4-Cyanobut-1ynyl]phenyl)-1-(2,4-dichlorophenyl)-4-methyl- $N$-(1,1-dioxo-thio-morpholino)-1H-pyrazole-3-carboxamide (AM6545) was synthesized from 1-(2,4-dichlorophenyl)-4-methyl-5-(4-iodophenyl)- $N$-(1,1-dioxothiomorpholino)- $1 H$-pyrazole-3-carboxamide and pent-4-ynenitrile based on reported procedures $(55,56) .{ }^{1} \mathrm{H}$ NMR (Varian Unity-INOVA spectrometer, $\left.500 \mathrm{MHz}, \mathrm{CDCl}_{3}\right): 8.08(\mathrm{~s}, 1 \mathrm{H}), 7.43(\mathrm{~s}, 1 \mathrm{H}), 7.37(\mathrm{~d}, \mathrm{~J}=7.81 \mathrm{~Hz}, 2 \mathrm{H})$, 7.28-7.34 (m, 1H), $7.24(\mathrm{~s}, 1 \mathrm{H}), 7.06(\mathrm{~d}, \mathrm{~J}=7.81 \mathrm{~Hz}, 2 \mathrm{H}), 3.56(\mathrm{~d}, \mathrm{~J}=4.88$ $\mathrm{Hz}, 4 \mathrm{H}), 3.26$ (br. s., 4H), 2.72-2.87 (m, 2H), 2.57-2.71 (m, 2H), 2.37 (s, $3 \mathrm{H}) ;{ }^{13} \mathrm{C} \mathrm{NMR}\left(125 \mathrm{MHz}, \mathrm{CDCl}_{3}\right): 161.21,144.23,143.94,136.69,136.25$, 133.36, 132.44, 130.97, 130.90, 129.92, 128.74, 128.49, 123.90, 118.92, $118.69,87.43,82.95,53.50,51.62,18.12,17.24,9.85$; HRMS-ESI (Q-TOF, Mass Spectrometry Laboratory, School of Chemical Sciences, University of Illinois, Urbana-Champaign, Illinois, USA) calculated for $\mathrm{C}_{26} \mathrm{H}_{23} \mathrm{Cl}_{2} \mathrm{~N}_{5} \mathrm{O}_{3} \mathrm{~S}$ $\left(\mathrm{M}^{+}+\mathrm{H}\right)$ : 556.0977: found: 556.0980. Elemental analysis (Robertson Microlit Laboratories) calculated for $\mathrm{C}_{26} \mathrm{H}_{23} \mathrm{Cl}_{2} \mathrm{~N}_{5} \mathrm{O}_{3} \mathrm{~S}$ : C\% 56.12, $\mathrm{H} \%$ 4.17, $\mathrm{N} \%$ 12.59, S\% 5.76; found: C\% 56.2, H\% 4.04, N\% 12.37, S\% 5.59.

Mice. Animal protocols were approved by the Institutional Animal Care and Use Committee of the NIAAA, NIH. Male 8- to 10-week old C57BL/6J mice and adult male genetically obese $o b / o b$ mice with their lean controls were obtained from The Jackson Laboratory. Mice were maintained under a 12-hour light/12-hour dark cycle and fed ad libitum. To generate DIO, C57BL/6J mice were fed either HFD (TD97070, Harlan Teklad; $60 \%$ of calories from fat, $18.8 \%$ from protein, and $21.3 \%$ from carbohydrates) or a standard laboratory diet (STD, NIH-31 rodent diet) for 14 or 20 weeks as indicated.

$\mathrm{CB} 1 \mathrm{R}^{-/-}$mice and their wild-type littermates were generated and backcrossed to a C57BL/6J background as described previously (57). For generation of liver $\mathrm{CB}_{1} \mathrm{R}$ transgenic mice on a global $C B 1 \mathrm{R}^{-/-}$background (btgCB1 $R^{-/-}$mice), a mouse cDNA containing the entire $C B 1 R$ reading frame was cloned into the XhoI and NotI sites of pGEMAlb-SVPA. A fragment containing the $C B 1 R$ coding region, the albumin enhancer, albumin promoter, and SV40 polyadenylation site was then excised from the construct at ApaI and MluI sites for microinjection into fertilized oocytes at the single-cell stage, derived from mating $\mathrm{CB}_{1 R^{-/-}}$parents. Transgenic offspring were identified by double-band genotyping using tail DNA and were mated to $C B 1 R^{-/-}$mice to generate mice that were heterozygous for the transgene, with their $C B 1 R^{-/-}$littermates serving as controls. Mice deficient in $M d r 1 a / b$ or in $M d r 1 a / b$ plus Bcrp/Abcg2 and their wild-type controls were from Taconic.

Experimental protocol. HFD-fed obese mice received vehicle, AM6545, or rimonabant daily for 28 days, either by i.p. injection of $10 \mathrm{mg} / \mathrm{kg}$ or gavage of 10 or $30 \mathrm{mg} / \mathrm{kg} / \mathrm{d}$, as indicated. Age-matched control mice on STD received vehicle daily. Body weight and food intake were monitored daily. Glucose tolerance and insulin resistance were determined as described below. Other mice were sacrificed by cervical dislocation; the brain, liver, and combined fat pads were removed, weighed, and snap-frozen; and trunk blood was collected for determining endocrine and biochemical parameters. Adiposity index was defined as the combined weight of the epididymal, retroperitoneal, and inguinal fat pads, expressed as a percentage of total body weight.

btgCB1 $R^{-/-}$mice and their $C B 1 R^{-/-}$littermates were kept on HFD for 20 weeks, with matched controls kept on STD. Mice were then treated daily for 7 days with vehicle or AM6545, $10 \mathrm{mg} / \mathrm{kg}$, i.p. Twelve hours after the last dose and following an overnight fast, the mice were tested for glucose tolerance and insulin resistance.

Adult male genetically obese $o b / o b$ mice were treated with AM6545 or rimonabant for 7 or 28 days, and hormonal and metabolic parameters were determined as in mice with DIO. 
Tissue levels of antagonists. For acute treatment, mice received a single dose $(10 \mathrm{mg} / \mathrm{kg}$, i.p. or po) of AM6545 or rimonabant and were sacrificed 1 hour later. Blood was collected, and the mice were perfused with phosphate buffered saline for 1 minute to remove drug from the intravascular space before removal of the brain and liver. For chronic treatment, mice received daily i.p. injections of $10 \mathrm{mg} / \mathrm{kg}$ of either antagonist for 28 days and were sacrificed 12 hours following the last dose. Drug levels in tissue homogenates and plasma were determined at Apredica Inc. using LC-MS/MS.

Radioligand binding assays. $\mathrm{AM} 6545$ binding to $\mathrm{CB}_{1} \mathrm{R}$ was assessed in competition displacement assays using $\left[{ }^{3} \mathrm{H}\right] \mathrm{CP}-55,940$ as the radioligand and crude membranes from mouse brain for $\mathrm{CB}_{1} \mathrm{R}$ or HEK293 cells stably transfected with the mouse $\mathrm{CB}_{2} \mathrm{R}$, as described previously (58). $K_{I}$ values were determined from 3 independent experiments performed in triplicate.

$\left[{ }^{35} S\right]$ GTP $\gamma$ S binding. Mouse brains were dissected and P2 membranes prepared (59) and resuspended at approximately $6 \mu \mathrm{g}$ protein $/ \mu \mathrm{l}$ in $1 \mathrm{ml}$ assay buffer (50 mM Tris $\mathrm{HCl}, 9 \mathrm{mM} \mathrm{MgCl} 2,0.2 \mathrm{mM}$ EGTA, $150 \mathrm{mM} \mathrm{NaCl}$; $\mathrm{pH}$ 7.4). Ligand-stimulated $\left[{ }^{35} \mathrm{~S}\right] \mathrm{GTP} \gamma \mathrm{S}$ binding was assayed as described previously (59). Briefly, membranes (10 $\mu$ g protein) were incubated in assay buffer containing $100 \mu \mathrm{M}$ GDP, $0.05 \mathrm{nM}\left[{ }^{35} \mathrm{~S}\right] \mathrm{GTP} \gamma \mathrm{S}$, test compounds (HU-210, AM6545, and rimonabant) at $1 \mathrm{nM}-1 \mu \mathrm{M}$, and $1.4 \mathrm{mg} / \mathrm{ml}$ fatty acid-free BSA in siliconized glass tubes. Bound ligand was separated from free ligand by vacuum filtration. Nonspecific binding was determined using $10 \mu \mathrm{M}$ GTPS. Basal binding was assayed in the absence of the ligand and in the presence of GDP.

Catalepsy test. Catalepsy was assayed using the bar test (29). Briefly, mice were removed from their home cage, and their forepaws were placed on a horizontal bar, $0.5 \mathrm{~cm}$ in diameter, positioned $4 \mathrm{~cm}$ above the bench surface. Vehicle-treated mice routinely let go of the bar within 2 seconds. Cataleptic behavior was defined as the time the animals remained motionless holding on to the bar, with an arbitrary cutoff of 30 seconds. The test was performed 15 minutes after drug administration.

Locomotor activity. Locomotor activity was quantified by the number of disruptions of infrared beams in 2 dimensions in an activity chamber.

Hypothermia. Mice were implanted with an intraabdominal thermoprobe, and core body temperature was monitored telemetrically. One hour after the i.p. administration of $10 \mathrm{mg} / \mathrm{kg}$ rimonabant or AM6545, the mice received a maximally effective i.p. or i.c.v. dose of the cannabinoid agonist WIN-55,212-2, and temperature was monitored for 8 hours.

EPM test. Anxiety-related behaviors were assessed using the EPM test as described previously (60), 1 hour after drug or vehicle administration. Time spent in the open or closed arms and number of entries was measured by using the automated HindSight software system.

Food intake and body weight. The amount of food eaten and body weight were recorded daily. For measuring the effect of leptin on food intake, mice on HFD (22 weeks) were treated for 9 days with AM6545 (10 mg/kg, i.p.) or vehicle. A third group of age-matched controls on STD were treated with vehicle for 9 days. After the final dosing, mice were fasted for 24 hours. Half an hour before the beginning of the dark phase, mice received leptin $(10 \mathrm{mg} / \mathrm{kg}$, i.p.) or vehicle, and food intake was measured for the indicated period of time.

Pairfeeding. Mice on HFD for 22 weeks were treated once daily with vehicle or with $10 \mathrm{mg} / \mathrm{kg}$ AM6545 i.p. for 1 week. In a third, pair-fed group, animals were fed the same amount of HFD as consumed by the AM6545treated animals over the preceding 24 hours. An i.p. glucose tolerance test (ipGTT) was performed on mice fasted overnight following the last treatment day, with an i.p. insulin tolerance test (ipITT) done on the next day in the fed state. One day later, blood was collected from infraorbital veins for serum glucose, insulin, and ALT measurements. Mice were sacrificed, and the liver was removed for TG measurements.

Blood chemistry. Blood was collected at the time the mice were sacrificed. Serum ALT, AST, and TGs were quantified by using IDEXX Vet Test Ana- lyzer 8008 (IDEXX Laboratories). Blood glucose was determined using the Elite glucometer (Bayer). Serum insulin was determined using the Ultra Sensitive Mouse Insulin ELISA kit (Crystal Chem Inc.). Serum leptin and adiponectin were determined by ELISA (ALPCO Diagnostics). HDL and LDL cholesterol were quantified colorimetrically using the EnzyChrom kit (BioAssay Systems).

Hepatic TG content. Liver tissue was extracted as described previously (61) and its TG content determined using the EnzyChrom Triglyceride Assay kit (BioAssay Systems).

Hepatic TG-rich VLDL secretion. Mice were fed HFD for 22 weeks, then treated for 7 days with AM6545 (10 mg/kg, i.p.) or vehicle. Mice were fasted overnight before measurement of VLDL-TG secretion into the systemic circulation as described previously (62). Briefly, Triton WR-1339 (100 mg/ $\mathrm{ml}$ in $0.9 \% \mathrm{NaCl}$; Sigma-Aldrich) was injected i.p. at $500 \mathrm{mg} / \mathrm{kg}$, and blood samples were collected at $0,1,2,3$ hours after injection from the infraorbital veins. The rate of a linear increase in VLDL-TG was adjusted to plasma volume as a measure of the total TG secretion rate (TGSR). The plasma volume (PV) was estimated from the linear relationship between body weight and plasma volume using the following the formula: $P V=$ body weight $(\mathrm{g})$ $\times 0.07$. TGSR was calculated from the slope of the TG concentration versus time curve and expressed as $\mathrm{mg} / \mathrm{kg} / \mathrm{h}$.

Glucose tolerance and insulin resistance tests. Mice fasted overnight were injected with glucose $(2 \mathrm{~g} / \mathrm{kg}$, i.p.), followed by tail blood collection at 0 , $15,30,45,60,90$, and 120 minutes. Blood glucose levels were determined using the Elite glucometer (Bayer). After blood glucose returned to baseline, the animals received an injection of insulin ( $0.75 \mathrm{U} / \mathrm{kg}$, i.p.; Eli Lilly), and blood glucose levels were determined at the same intervals as above, except for the pair-feeding experiments, for which insulin resistance was assessed on the following day. $\mathrm{AUC}_{\text {glucose }}$ and $\mathrm{AUC}_{\text {insulin }}$ between 0 and 120 minutes were determined using a trapezoidal model (63).

Indirect calorimetry and locomotor activity. $\mathrm{O}_{2}$ consumption and $\mathrm{CO}_{2}$ production were monitored by indirect calorimetry (Oxymax, Columbus Instruments) with 1 mouse per chamber. Each chamber was equipped with a 2-dimensional ( $x y$ ) infrared beam system (OPTO-M3) to record locomotor activity. Conditioned fresh air at $21 \pm 0.5^{\circ} \mathrm{C}$ and $55 \% \pm 5 \%$ relative humidity was pumped into the chambers at $0.6 \mathrm{l} / \mathrm{min}$. The animals were acclimated to the chambers for 1 day, and $\mathrm{VO}_{2}$ and $\mathrm{VCO}_{2}$ measurements taken every 30 minutes were collected and recorded on a computer over the next 24 hours. During the 12-hour dark/12-hour light phases, mice had free access to food and water. AM6545, rimonabant (each at $10 \mathrm{mg} / \mathrm{kg}$, i.p.), or vehicle were administered at the beginning of the light phase, and the mice were monitored for an additional 12 hours. RQ was calculated as $\mathrm{CO}_{2}\left(\mathrm{VCO}_{2}\right)$ production $/ \mathrm{O}_{2}\left(\mathrm{VO}_{2}\right)$ consumption, with the values of 1 or 0.7 indicating $100 \% \mathrm{CHO}$ or $100 \%$ fat oxidation (FO), respectively. Total energy expenditure (TEE) was calculated as $\mathrm{VO}_{2} \cdot(3.815+1.232 \cdot \mathrm{RQ})$, normalized to (body mass) ${ }^{0.75}$, and expressed as $\mathrm{kcal} / \mathrm{h} / \mathrm{kg}^{0.75}$. FO and $\mathrm{CHO}$ were calculated (64) as: $\mathrm{FO}=1.69 \cdot \mathrm{VO}_{2}-1.69 \cdot \mathrm{VCO}_{2}$ and $\mathrm{CHO}=4.57 \cdot \mathrm{VCO}_{2}$ $-3.23 \cdot \mathrm{VO}_{2}$ and expressed as $\mathrm{g} / \mathrm{h} / \mathrm{kg}^{0.75}$.

Western blotting. The relative tissue content of $\mathrm{CB}_{1} \mathrm{R}$ protein was assessed by Western blotting (65), using an antibody against a peptide corresponding to aa $1-14$ of the extracellular $\mathrm{N}$-terminus of the $\mathrm{CB}_{1} \mathrm{R}$ (Cayman Chemical), a region displaying $100 \%$ sequence homology between the rodent an human receptor.

$R T-P C R$. CB1R mRNA expression was assessed by RT-PCR and normalized with $\beta$-actin. Total RNA was isolated from mouse brain and liver tissue using TRIzoL and reverse transcribed using the SuperScript First-Strand Synthesis System (Invitrogen). The resulting single-stranded cDNA $(5 \mu \mathrm{l})$ was denatured at $95^{\circ} \mathrm{C}$ for 3 minutes and subjected to 30 cycles of amplification, each consisting of 15 seconds at $94^{\circ} \mathrm{C}, 30$ seconds at $50^{\circ} \mathrm{C}$, and 1 minute at $72^{\circ} \mathrm{C}$, with a 7 -minute final extension at $72^{\circ} \mathrm{C}$. The following 
forward and reverse primers were used: $\mathrm{CB}_{1}$ (U22948), 5'-GTACCATCACCACAGACCTCCTC-3' and 5'-GGATTCAGAATCATGAAGCACTCCA-3' (300-bp amplicon); and mouse $\beta$-actin $5^{\prime}$-AAGGTGACAGCATTGCTTCT$3^{\prime}$ and 5'-GGCTGCCTCAACACCTCA-3' (189-bp amplicon). PCR products were separated by electrophoresis on a $1 \%$ agarose gel. RNA without reverse transcription did not yield any amplicon, indicating the absence of genomic DNA contamination.

Real-time PCR. Total mRNA from liver, inguinal, and epididymal adipose tissue was extracted using the RNeasy kit (QIAGEN) followed by DNase I treatment (Invitrogen) and reverse-transcribed using the Iscript cDNA kit (Bio-Rad). Real-time PCR was performed using a Bio-Rad iCycler iQ and the QuantiTect Primer Assays (QT00169057, QT00149240, QT00291151, QT01748831, QT01554441, and QT00106820) against mouse HSL, FAS, Scd1, CB1R, Acaca, and CPT1, respectively. The normalization was performed with the QuantiTect Primer Assay against mouse Gapdh (QT01658692).

Materials. Rimonabant and CP-55,940 were obtained from the National Institute of Drug Abuse Drug Supply Program. HU-210 and WIN55,212-2 were purchased from Tocris. All compounds were dissolved in DMSO using gentle heating before being diluted with Tween 80 and saline (4\% DMSO; $1 \%$ Tween 80 ; $95 \%$ saline) for i.p. injections or oral administration by gavage.

Statistics. Values are expressed as mean \pm SEM. Unpaired 2-tailed Student's $t$ test was used to determine differences between vehicle- and com- pound-treated groups. Time-dependent variables were analyzed, and results in multiple groups were compared by ANOVA followed by Bonferroni test. Nonlinear regression analysis was used to determine the $K_{I}$ values of ligands in binding assays (GraphPad Prism version 5 for Windows). $P$ values less than 0.05 were considered significant.

\section{Acknowledgments}

This work was supported by the NIH (intramural funds from the NIAAA to G. Kunos and from the NCI to S.V. Ambudkar, and 2R01 DA007215 to A. Makriyannis). We thank Christoph Buettner for helpful discussions.

Received for publication February 3, 2010, and accepted in revised form May 19, 2010.

Address correspondence to: George Kunos, Laboratory of Physiologic Studies, National Institute on Alcohol Abuse and Alcoholism, National Institutes of Health, Bethesda, Maryland 20892, USA. Phone: 301.443.2069; Fax: 301.480.0257; E-mail: gkunos@mail.nih. gov. Or to: Alexandros Makriyannis, Center for Drug Discovery, Northeastern University, Boston, Massachusetts 02115, USA. Phone: 617.373.4200; Fax: 617.373.7493; E-mail: a.makriyannis@neu.edu.
1. Pacher P, Batkai S, Kunos G. The endocannabinoid system as an emerging target of pharmacotherapy. Pharmacol Rev. 2006;58(3):389-462.

2. Di Marzo V. The endocannabinoid system in obesity and type 2 diabetes. Diabetologia. 2008; 51(8):1356-1367.

3. Di Marzo V, et al. Role of insulin as a negative regulator of plasma endocannabinoid levels in obese and nonobese subjects. Eur J Endocrinol. 2009; 161(5):715-722.

4. Engeli $S$, et al. Activation of the peripheral endocannabinoid system in human obesity. Diabetes. 2005; 54(10):2838-2843.

5. Bluher M, et al. Dysregulation of the peripheral and adipose tissue endocannabinoid system in human abdominal obesity. Diabetes. 2006;55(11):3053-3060.

6. Ravinet Trillou C, et al. Anti-obesity effect of SR141716, a CB1 receptor antagonist, in diet-induced obese mice. Am J Physiol Regul Integr Comp Physiol. 2003;284(2):R345-R353.

7. Gary-Bobo M, et al. Rimonabant reduces obesityassociated hepatic steatosis and features of metabolic syndrome in obese Zucker fa/fa rats. Hepatology. 2007;46(1):122-129.

8. Van Gaal LF, Rissanen AM, Scheen AJ, Ziegler O, Rossner S. Effects of the cannabinoid-1 receptor blocker rimonabant on weight reduction and cardiovascular risk factors in overweight patients: 1-year experience from the RIO-Europe study. Lancet. 2005;365(9468):1389-1397.

9. Despres JP, Golay A, Sjostrom L. Effects of rimonabant on metabolic risk factors in overweight patients with dyslipidemia. NEnglJ Med. 2005;353(20):2121-2134.

10. Pi-Sunyer FX, Aronne LJ, Heshmati HM, Devin J, RosenstockJ. Effect of rimonabant, a cannabinoid-1 receptor blocker, on weight and cardiometabolic risk factors in overweight or obese patients: RIONorth America: a randomized controlled trial. JAMA. 2006;295(7):761-775.

11. Addy $\mathrm{C}$, et al. The acyclic cb1r inverse agonist taranabant mediates weight loss by increasing energy expenditure and decreasing caloric intake. Cell Metab. 2008;7(1):68-78.

12. Christensen R, Kristensen PK, Bartels EM, Bliddal $\mathrm{H}$, Astrup A. Efficacy and safety of the weight-loss drug rimonabant: a meta-analysis of randomised trials. Lancet. 2007;370(9600):1706-1713.

13. Jones D. End of the line for cannabinoid receptor 1 as an anti-obesity target? Nat Rev Drug Discov. 2008; 7(12):961-962.

14. Moreira FA, Lutz B. The endocannabinoid system: emotion, learning and addiction. Addict Biol. 2008; 13(2):196-212.

15. Osei-Hyiaman D, et al. Endocannabinoid activation at hepatic CB1 receptors stimulates fatty acid synthesis and contributes to diet-induced obesity. J Clin Invest. 2005;115(5):1298-1305.

16. Jourdan T, Djaouti L, Demizieux L, Gresti J, Verges B, Degrace P. CB1 antagonism exerts specific molecular effects on visceral and subcutaneous fat and reverses liver steatosis in diet-induced obese mice. Diabetes. 2010;59(4):926-934.

17. Xu X, et al. Overexpression of cannabinoid receptors CB1 and CB2 correlates with improved prognosis of patients with hepatocellular carcinoma. Cancer Genet Cytogenet. 2006;171(1):31-38.

18. Pagotto U, Marsicano G, Cota D, Lutz B, Pasquali $\mathrm{R}$. The emerging role of the endocannabinoid system in endocrine regulation and energy balance. Endocr Rev. 2006;27(1):73-100.

19. Eckardt K, et al. Cannabinoid type 1 receptors in human skeletal muscle cells participate in the negative crosstalk between fat and muscle. Diabetologia. 2009;52(4):664-674.

20. Nakata M, Yada T. Cannabinoids inhibit insulin secretion and cytosolic $\mathrm{Ca}(2+)$ oscillation in islet beta-cells via CB1 receptors. Regul Pept. 2008;145(1-3):49-53.

21. Bermudez-Silva FJ, et al. Presence of functional cannabinoid receptors in human endocrine pancreas. Diabetologia. 2008;51(3):476-487.

22. Cota $D$, et al. The endogenous cannabinoid system affects energy balance via central orexigenic drive and peripheral lipogenesis. J Clin Invest. 2003; 112(3):423-431.

23. Bensaid $M$, et al. The cannabinoid CB1 receptor antagonist SR141716 increases Acrp30 mRNA expression in adipose tissue of obese $\mathrm{fa} / \mathrm{fa}$ rats and in cultured adipocyte cells. Mol Pharmacol. 2003; 63(4):908-914.

24. Osei-Hyiaman D, et al. Hepatic $\mathrm{CB}(1)$ receptor is required for development of diet-induced steatosis, dyslipidemia, and insulin and leptin resistance in mice. J Clin Invest. 2008;118(9):3160-3169.

25. Ruby MA, et al. Overactive endocannabinoid signaling impairs apolipoprotein E-mediated clearance of triglyceride-rich lipoproteins. Proc Natl Acad
Sci US A. 2008;105(38):14561-14566.

26. Nogueiras R, et al. Peripheral, but not central, CB1 antagonism provides food intake-independent metabolic benefits in diet-induced obese rats. Diabetes. 2008;57(11):2977-2991.

27. Ambudkar SV, Dey S, Hrycyna CA, Ramachandra M, Pastan I, Gottesman MM. Biochemical, cellular, and pharmacological aspects of the multidrug transporter. Annu Rev Pharmacol Toxicol. 1999; 39:361-398.

28. van Breemen RB, Li Y. Caco-2 cell permeability assays to measure drug absorption. Expert Opin Drug Metab Toxicol. 2005;1(2):175-185.

29. Martin BR, et al. Behavioral, biochemical, and molecular modeling evaluations of cannabinoid analogs. Pharmacol Biochem Behav. 1991;40(3):471-478.

30. Agarwal N, et al. Cannabinoids mediate analgesia largely via peripheral type 1 cannabinoid receptors in nociceptors. Nat Neurosci. 2007;10(7):870-879.

31. Dziadulewicz EK, et al. Naphthalen-1-yl-(4-pentyloxynaphthalen-1-yl)methanone: a potent, orally bioavailable human CB1/CB2 dual agonist with antihyperalgesic properties and restricted central nervous system penetration. J Med Chem. 2007;50(16):3851-3856.

32. Izzo AA, Coutts AA. Cannabinoids and the digestive tract. In Pertwee R, ed. Cannabinoids. New York, New York, USA: Heidelberg: Springer Berlin Heidelberg; 2005:573-598.

33. Calignano A, La Rana G, Makriyannis A, Lin SY, Beltramo M, Piomelli D. Inhibition of intestinal motility by anandamide, an endogenous cannabinoid. Eur J Pharmacol. 1997;340(2-3):R7-R8.

34. Osei-Hyiaman D, et al. Hepatic CB1 receptor is required for development of diet-induced steatosis, dyslipidemia, and insulin and leptin resistance in mice. J Clin Invest. 2008;118(9):3160-3169.

35. Ozcan U, et al. Endoplasmic reticulum stress links obesity, insulin action, and type 2 diabetes. Science. 2004;306(5695):457-461.

36. Jbilo O, et al. The CB1 receptor antagonist rimonabant reverses the diet-induced obesity phenotype through the regulation of lipolysis and energy balance. FASEB J. 2005;19(11):1567-1569.

37. Di Marzo V, et al. Leptin-regulated endocannabinoids are involved in maintaining food intake. Nature. 2001;410(6830):822-825.

38. Watanabe $\mathrm{T}$, et al. Rimonabant ameliorates insulin 
resistance via both adiponectin-dependent and adiponectin-independent pathways. J Biol Chem. 2009; 284(3):1803-1812.

39. Ishac EJ, Jiang L, Lake KD, Varga K, Abood ME, Kunos G. Inhibition of exocytotic noradrenaline release by presynaptic cannabinoid CB1 receptors on peripheral sympathetic nerves. BrJ Pharmacol. 1996; 118(8):2023-2028.

40. Gonthier MP, et al. Identification of endocannabinoids and related compounds in human fat cells. Obesity (Silver Spring). 2007;15(4):837-845.

41. Quarta C, et al. CB1 signaling in forebrain and sympathetic neurons is a key determinant of endocannabinoid actions on energy balance. Cell Metabolism. 2010;11(4):273-285.

42. Buettner C, et al. Leptin controls adipose tissue lipogenesis via central, STAT3-independent mechanisms. Nat Med. 2008;14(6):667-675.

43. Herling AW, et al. CB1 receptor antagonist AVE1625 affects primarily metabolic parameters independently of reduced food intake in Wistar rats. Am J Physiol Endocrinol Metab. 2007;293(3):E826-E832.

44. Richey JM, et al. Rimonabant prevents additional accumulation of visceral and subcutaneous fat during high-fat feeding in dogs. Am J Physiol Endocrinol Metab. 2009;296(6):E1311-E1318.

45. El-Haschimi K, Pierroz DD, Hileman SM, Bjorbaek C, Flier JS. Two defects contribute to hypothalamic leptin resistance in mice with diet-induced obesity. J Clin Invest. 2000;105(12):1827-1832.

46. Van Heek M, et al. Diet-induced obese mice develop peripheral, but not central, resistance to leptin. J Clin Invest. 1997;99(3):385-390.

47. Ravinet Trillou C, Delgorge C, Menet C, Arnone M, Soubrie P. CB1 cannabinoid receptor knockout in mice leads to leanness, resistance to diet-induced obesity and enhanced leptin sensitivity. Int J Obes
Relat Metab Disord. 2004;28(4):640-648.

48. Minokoshi Y, et al. Leptin stimulates fatty-acid oxidation by activating AMP-activated protein kinase. Nature. 2002;415(6869):339-343.

49. Tedesco L, et al. Cannabinoid type 1 receptor blockade promotes mitochondrial biogenesis through endothelial nitric oxide synthase expression in white adipocytes. Diabetes. 2008;57(8):2028-2036.

50. Scheen AJ, Finer N, Hollander P, Jensen MD, Van Gaal LF. Efficacy and tolerability of rimonabant in overweight or obese patients with type 2 diabetes: a randomised controlled study. Lancet. 2006; 368(9548):1660-1672.

51. LoVerme J, et al. Synthesis and characterization of a peripherally restricted CB1 cannabinoid antagonist, URB 447, that reduces feeding and bodyweight gain in mice. Bioorg Med Chem Lett. 2009; 19(3):639-643.

52. Son MH, et al. Peripherally acting CB1-receptor antagonist: the relative importance of central and peripheral CB1 receptors in adiposity control. Int J Obes (Lond). 2010;34(3):547-556.

53. Receveur JM, et al. Conversion of 4-cyanomethylpyrazole-3-carboxamides into CB1 antagonists with lowered propensity to pass the blood-brainbarrier. Bioorg Med Chem Lett. 2010;20(2):453-457.

54. Sink KS, et al. The novel cannabinoid CB1 receptor neutral antagonist AM4113 suppresses food intake and food-reinforced behavior but does not induce signs of nausea in rats. Neuropsychopharmacology. 2008;33(4):946-955.

55. Alami M, Ferri F, Linstrumelle G. An efficient palladium-catalysed reaction of vinyl and aryl halides or triflates with terminal alkynes. Tetrahedron Lett. 1993;34(40):6403-6406

56. Lan R, et al. Structure-activity relationships of pyrazole derivatives as cannabinoid receptor antago- nists. J Med Chem. 1999;42(4):769-776.

57. Zimmer A, Zimmer AM, Hohmann AG, Herkenham $\mathrm{M}$, Bonner TI. Increased mortality, hypoactivity, and hypoalgesia in cannabinoid CB1 receptor knockout mice. Proc Natl Acad Sci U S A. 1999;96(10):5780-5785

58. Lan R, et al. Design and synthesis of the CB1 selective cannabinoid antagonist AM281: a potential human SPECT ligand. AAPS PharmSci. 1999;1(2):E4.

59. Griffin G, Atkinson PJ, Showalter VM, Martin BR, Abood ME. Evaluation of cannabinoid receptor agonists and antagonists using the guanosine-5' O-(3-[35S]thio)-triphosphate binding assay in rat cerebellar membranes. J Pharmacol Exp Ther. 1998; 285(2):553-560.

60. Hefner K, Holmes A. Ontogeny of fear-, anxietyand depression-related behavior across adolescence in C57BL/6J mice. Behav Brain Res. 2007; 176(2):210-215.

61. Folch J, Lees M, Sloane Stanley GH. A simple method for the isolation and purification of total lipides from animal tissues. J Biol Chem. 1957;226(1):497-509.

62. Lopez-Parra M, et al. Regulatory effects of arachidonate 5-lipoxygenase on hepatic microsomal TG transfer protein activity and VLDL-triglyceride and apoB secretion in obese mice. J Lipid Res. 2008; 49(12):2513-2523.

63. Chung J, et al. HSP72 protects against obesityinduced insulin resistance. Proc Natl Acad Sci US A. 2008;105(5):1739-1744.

64. Moverare-Skrtic S, et al. Dihydrotestosterone treatment results in obesity and altered lipid metabolism in orchidectomized mice. Obesity (Silver Spring). 2006; 14(4):662-672.

65. Liu J, et al. Functional CB1 cannabinoid receptors in human vascular endothelial cells. Biochem J. 2000; 346(pt 3):835-840. 